\title{
Efficient near-infrared quantum cutting by cooperative energy transfer in $\mathrm{Bi}_{3} \mathrm{TeBO}_{9}: \mathrm{Nd}^{3+}$ phosphors
}

\author{
T. Zhezhera ${ }^{1}$ (D), P. Gluchowski ${ }^{2}$ (D), M. Nowicki ${ }^{1,3}$ (D) M. Chrunik $^{4}$ (D) A. Majchrowski ${ }^{4}$ (D), \\ K. M. Kosyl ${ }^{5}$ (D), and D. Kasprowicz ${ }^{1, \star}$ (D)
}

${ }^{1}$ Faculty of Materials Engineering and Technical Physics, Poznan University of Technology, Piotrowo 3, 60-965 Poznan, Poland

${ }^{2}$ Institute of Low Temperature and Structure Research of Polish Academy of Sciences, Okólna 2, 50-422 Wroclaw, Poland

${ }^{3}$ Center for Advanced Technology, Adam Mickiewicz University, Uniwersytetu Poznańskiego 10, 61-614 Poznan, Poland

${ }^{4}$ Institute of Applied Physics, Military University of Technology, Kaliskiego 2, 00-908 Warsaw, Poland

${ }^{5}$ Institute of Physics, Polish Academy of Sciences, Aleja Lotników 32/46, 02-668 Warsaw, Poland

Received: 10 July 2021

Accepted: 15 October 2021

Published online:

3 January 2022

(C) The Author(s) 2021

\begin{abstract}
An efficient near-infrared quantum cutting process by cooperative down-conversion of active $\mathrm{Bi}^{3+}$ and $\mathrm{Nd}^{3+}$ ions was demonstrated in $\mathrm{Bi}_{3} \mathrm{TeBO}_{9}: \mathrm{Nd}^{3+}$ phosphors. In particular, the near-infrared emission of $\mathrm{Nd}^{3+}$ ions enhanced by $\mathrm{Bi}^{3+}$ ions of a series of novel $\mathrm{Bi}_{3} \mathrm{TeBO}_{9}: \mathrm{Nd}^{3+}$ microcrystalline powders doped with $\mathrm{Nd}^{3+}$ ions in various concentrations was investigated. In order to investigate the luminescent properties of BTBO: $\mathrm{Nd}^{3+}$ powders, the excitation and emission spectra and the fluorescence decay time were measured and analyzed. In particular, the emission of $\mathrm{Bi}_{3} \mathrm{TeBO}_{9}: \mathrm{Nd}^{3+}$ at 890 and $1064 \mathrm{~nm}$ was excited at $327 \mathrm{~nm}$ (via energy transfer from $\mathrm{Bi}^{3+}$ ions) and at $586.4 \mathrm{~nm}$ (directly by $\mathrm{Nd}^{3+}$ ions). The highest intensity emission bands in near-infrared were detected in the spectra of $\mathrm{Bi}_{3} \mathrm{TeBO}_{9}: \mathrm{Nd}^{3+}$ doped with 5.0 and 0.5 at.\% of $\mathrm{Nd}^{3+}$ ions upon excitation in ultraviolet and visible spectral range, respectively. The fluorescence decay lifetime monitored at $1064 \mathrm{~nm}$ for $\mathrm{Bi}_{3} \mathrm{TeBO}_{9}: \mathrm{Nd}^{3+}$ powders shows the single- or double-exponential character depending on the concentrations of $\mathrm{Nd}^{3+}$ ions. The possible mechanisms of energy relaxation after excitation $\mathrm{Bi}_{3} \mathrm{TeBO}_{9}: \mathrm{Nd}^{3+}$ powders in ultraviolet or visible spectral range were discussed. The investigated $\mathrm{Bi}_{3} \mathrm{TeBO}_{9}: \mathrm{Nd}^{3+}$ phosphors efficiently concentrate the ultraviolet/visible radiation in the near-infrared spectral range and can be potentially used as effective spectral converters.
\end{abstract}

Handling Editor: David Cann.

Address correspondence to E-mail: dobroslawa.kasprowicz@put.poznan.pl 


\section{GRAPHICAL ABSTRACT}

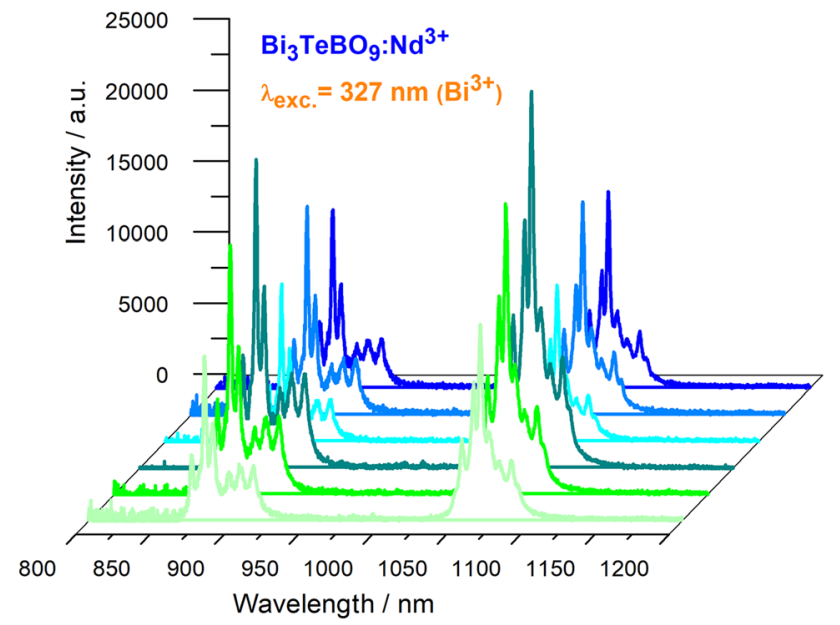

\section{Introduction}

The efficiency of spectral converters based on rare earth (RE) ions doped crystalline materials is related to the characteristic energy level structures of $\mathrm{RE}$ ions, which allows up- and/or down-conversion processes by resonant energy transfer between lanthanide ions [1]. Besides many other applications of such materials, they can be used in the solar cells technology to achieve high efficiency in conversion of solar energy into electric current, by the concentration of solar radiation in the appropriate spectral range, leading thus to enhancement of the photovoltaic effect. Solar energy near the Earth's surface is distributed in a wide spectral range from 300 to $2500 \mathrm{~nm}$ and consists of ultraviolet (UV) in 7\%, visible (VIS) in $47 \%$ and infrared (IR) in $46 \%$ radiation [2]. Conventional single-junction semiconductor solar cells effectively convert only the photons of energies close to the semiconductor band gap $\left(\mathrm{E}_{\mathrm{g}}\right)$ as a result of the mismatch between the incident solar spectrum range and the spectral absorption range of the semiconductor material [3]. The photons with energies smaller than $\mathrm{E}_{\mathrm{g}}$ are not absorbed and their energy is not used for electrons generation, while the photons with energies higher than $E_{g}$ are absorbed, but the excess energy is lost due to thermalization of the generated electrons [4]. These spectral losses in a single-junction crystalline silicon (c-Si) solar cells limit the efficiency of solar energy conversion into electricity. One of the solutions to overcome this limitation is to use the RE doped materials as spectral converters in c-Si solar cells technology, which concentrate the solar radiation into the required NIR spectral range in the process of down-conversion (known as quantum cutting process) [1]. In other words, the high-energy region of the solar spectrum cannot be utilized by conventional c-Si solar cells as silicon has a band gap $\mathrm{E}_{\mathrm{g}}=1.12 \mathrm{eV}$, corresponding to the absorption in the NIR spectral range $\approx 1100 \mathrm{~nm}$ [5]. The proposed solution is to convert the high-energy part of the solar spectrum into the low energy NIR region, from which the solar energy can be efficiently absorbed by the c-Si solar cells.

In this study, we used a complex borate $\mathrm{Bi}_{3} \mathrm{TeBO}_{9}$ (abbreviated as BTBO) micro-crystals doped with $\mathrm{Nd}^{3+}$ ions. Oxide crystals are considered important for photonic applications, thanks to the excellent transparency window from UV to NIR as well as high $\mathrm{RE}^{3+}$ doping ability [6-8]. The synthesis, crystal structure, electronic structure, some optical and spectroscopic properties of undoped BTBO were already reported [9-12]. Recently, the first complex study of vibrational properties based on experimental results of IR and Raman spectroscopy supported by the ab initio calculations for undoped BTBO microcrystalline powders were reported by us [13]. 
Among the $\mathrm{RE}^{3+}$ ions, $\mathrm{Nd}^{3+}$ ones are particularly attractive as spectral converters because of their characteristic electronic energy level structure, which allows efficient down-conversion of the electromagnetic spectrum from UV/VIS to NIR [14]. In this study the specific $\mathrm{Nd}^{3+}$ emissions of the ${ }^{4} \mathrm{~F}_{3 / 2} \rightarrow{ }^{4} \mathrm{I}_{9 / 2}$ and ${ }^{4} \mathrm{~F}_{3 / 2} \rightarrow{ }^{4} \mathrm{I}_{11 / 2}$ transitions under excitation in UV and VIS spectral range were investigated in BTBO: $\mathrm{Nd}^{3+}$ system. Moreover, there are many reports available on the use of $\mathrm{Bi}^{3+}$ ions (present in BTBO matrix) as sensitizers for $\operatorname{RE}^{3+}$ ions $[15,16]$. The ground state of $\mathrm{Bi}^{3+}$ ion with $6 \mathrm{~s}^{2}$ electronic configuration is expressed as ${ }^{1} \mathrm{~S}_{0}$. The $6 \mathrm{~s} 6 \mathrm{p}$ excited states consist of ${ }^{1} \mathrm{P}_{1},{ }^{3} \mathrm{P}_{2},{ }^{3} \mathrm{P}_{1}$ and ${ }^{3} \mathrm{P}_{0}$ states. The transition from ${ }^{1} \mathrm{P}_{1}$ to the ground state generally occurs in the UV region, whereas the location of the emission band originating from ${ }^{3} \mathrm{P}_{1}$ and ${ }^{3} \mathrm{P}_{0}$ can be observed in the range of shorter wavelengths (in UV or VIS range) depending on the host lattice. Although the transition from the ground state to the first excited level $\left({ }^{1} \mathrm{~S}_{0} \rightarrow{ }^{3} \mathrm{P}_{0}\right)$ of $\mathrm{Bi}^{3+}$ is strongly forbidden, the transitions from the ${ }^{1} \mathrm{~S}_{0}$ ground state to the ${ }^{3} \mathrm{P}_{2},{ }^{3} \mathrm{P}_{1}$ and ${ }^{3} \mathrm{P}_{0}$ states are observed in optical excitation spectra. Depending on the host material, the structure of the energy levels of $\mathrm{Bi}^{3+}$ ions may change and a lowering of the excited states energy is typically observed in comparison with the structure of electronic levels of isolated $\mathrm{Bi}^{3+}$ ions [17-19]. Particularly, for oxidebased lattices, the structure of electronic levels of $\mathrm{Bi}^{3+}$ ions strongly depends on the configuration of the nearest oxygen surrounding of $\mathrm{Bi}^{3+}$ ions [17]. In the $\mathrm{BTBO}$ structure, $\mathrm{Bi}^{3+}$ ions occur in octahedral coordination $\mathrm{BiO}_{6}$ being six-coordinated by the oxygen atoms forming $\mathrm{BiO}_{6}$ octahedra [13]. Due to the close location of some excited states of $\mathrm{Bi}^{3+}$ and $\mathrm{Nd}^{3+}$ ions in the considered BTBO: $\mathrm{Nd}^{3+}$ system, the orbitals for energy transfer from the $\mathrm{Bi}^{3+}$ to the $\mathrm{RE}^{3+}$ levels overlap and an efficient NIR quantum-cutting process (converting photons of high energy into photons of lower energy) is possible [15]. Thus, the synergy effect of cooperative down-conversion of $\mathrm{Bi}^{3+}$ and $\mathrm{Nd}^{3+}$ ions from UV/VIS to NIR spectral range results in efficient NIR emission in BTBO: $\mathrm{Nd}^{3+}$ system.

Efficiency of the spectral conversion of the proposed BTBO: $\mathrm{Nd}^{3+}$ system strongly depends on the concentration of $\mathrm{RE}^{3+}$ active ions. Usually, increase in the $\mathrm{RE}^{3+}$ ions concentration should improve the luminescence. However, too short distances between the active $\mathrm{RE}^{3+}$ ions in the host matrix may increase the probability of energy transfer between them, which results in luminescence suppression. This phenomenon, known as Luminescence Concentration Quenching (LCQ), was widely observed in lanthanide-based luminescent materials [20, 21], but it can be avoided by using limited $\mathrm{RE}^{3+}$ concentration $[22,23]$. To obtain the optimal concentration of active $\mathrm{Nd}^{3+}$ ions, we investigated BTBO microcrystalline powders doped with different concentrations of $\mathrm{Nd}^{3+}$ ions $(0.5,1.0,2.5,5.0,7.5$ and 10.0 at. \%). On the other hand, another condition required for efficient $\mathrm{RE}^{3+}$ luminescence emission of the doped phosphors is a long emission lifetime, which significantly depends on the lack of radiationless transitions. The phosphors radiationless transition occurs due to the multiphonon relaxation from the excited states of active ions to the matrix, or to the above-mentioned energy transfer process between the excited and unexcited states of $\mathrm{RE}^{3+}$ active ions. These processes may also quench the emission of $\mathrm{RE}^{3+}$ active ions and are undesirable for achieving efficient emissions of $\mathrm{RE}^{3+}$ ions in the host matrix. The most desirable are the matrices with lower phonon energy as well as optimal separation between the active dopant ions. Raman investigation presented in this paper shows that BTBO has a low-energy phonon matrix.

The mentioned above new BTBO: $\mathrm{Nd}^{3+}$ powders were synthesized by means of the modified Pechini method. In this paper we present for the first time the synthesis as well as structure, morphology, $\mu$-Raman and luminescence properties of BTBO: $\mathrm{Nd}^{3+}$ powders. In particular, the excitation spectra monitored at $1064 \mathrm{~nm}$, emission in NIR under excitation at 327 and $586.4 \mathrm{~nm}$ as well as decay lifetimes monitored at $1064 \mathrm{~nm}$ for BTBO: $\mathrm{Nd}^{3+}$ powders are presented. Moreover, the energy transfer mechanism between $\mathrm{Bi}^{3+}$ and $\mathrm{Nd}^{3+}$ ions, which leads to NIR emission of BTBO: $\mathrm{Nd}^{3+}$, was discussed. Additionally, using the Inokuti-Hirayama model, the kinetics of the luminescence was analyzed and some parameters related with the energy transfer processes (from excited to neighboring unexcited $\mathrm{Nd}^{3+}$ ions) were determined for BTBO: $\mathrm{Nd}^{3+}$ powder (0.5 at.\%).

\section{Synthesis procedure}

BTBO powders were synthesized by means of the modified Pechini method [24]. The following precursor materials were used for the synthesis without additional purification: commercial bismuth oxide 
$\left(\mathrm{Bi}_{2} \mathrm{O}_{3}\right.$, SIAL, $\left.99.9 \%\right)$, tellurium dioxide $\left(\mathrm{TeO}_{2}\right.$, MERCK, 99.99\%), neodymium oxide $\left(\mathrm{Nd}_{2} \mathrm{O}_{3}\right.$, ALFA $99.999 \%)$, boric acid $\left(\mathrm{H}_{3} \mathrm{BO}_{3}\right.$, STENMARK, $\left.99.5 \%\right)$, citric acid $\left(\mathrm{C}_{6} \mathrm{H}_{8} \mathrm{O}_{7} \cdot \mathrm{H}_{2} \mathrm{O}, \mathrm{POCH}, 99.4 \%\right)$, mannitol $\left(\mathrm{C}_{6} \mathrm{H}_{8}(\mathrm{OH})_{6}\right.$, CHEMDREAMLAND, 99.5\%), deionized water (MILIPORE, resistivity $\rho=15 \mathrm{M} \Omega \cdot \mathrm{cm}$ ) and nitric acid $\left(\mathrm{HNO}_{3}, 65 \%\right.$ wt., $\mathrm{POCH}$, pure p.a.). In order to prepare the initial solutions, the proper quantities of the oxides: $\mathrm{Bi}_{2} \mathrm{O}_{3}$, (along with proper amount of $\mathrm{Nd}_{2} \mathrm{O}_{3}$ dopant) and $\mathrm{TeO}_{2}$ were dissolved in a minimal volume of $\mathrm{HNO}_{3}$ in the presence of citric acid (complexing agent) upon stirring and heating at $80{ }^{\circ} \mathrm{C}$. Tellurium source must be provided in proper excess (here $12 \%$ mol.) because of its considerable volatility during pyrolysis in the Pechini method (not observed while heating the individual raw substrate). Citric acid was chosen as a complexing agent because citrate ligands can form rather stable complexes of both $\mathrm{Bi}^{3+}$ and $\mathrm{Te}^{4+}$ in strongly acidic solutions as well as of $\mathrm{Nd}^{3+}$ ions [25]. The molar ratio between citric acid and metal cations was set to be 3:1. Under these conditions, the complete dissolution of the metal oxides was secured. When transparent and homogeneous solutions containing metal complexes were obtained, a proper amount of $\mathrm{H}_{3} \mathrm{BO}_{3}$ (with required $10.0 \%$ mol. boron excess applied to prevent non-stoichiometry due to the presence of adsorbed water and a possible evaporation of $\mathrm{B}_{2} \mathrm{O}_{3}$ at elevated temperatures) was charged into the solution and the stirring was kept on. The overall molar ratio of the used $\mathrm{Bi}_{2} \mathrm{O}_{3}, \mathrm{TeO}_{2}$ and $\mathrm{H}_{3} \mathrm{BO}_{3}$ substrates was 3:2.24:2.2, respectively (counted for undoped BTBO). After secondary homogenization, mannitol (polymeric agent) was added into the solution. In all the syntheses carried out, the molar ratio of citric acid to mannitol was constant and set to 3:1. After dissolving all the reagents, the solution mixing was continued for about $1 \mathrm{~h}$ at $90{ }^{\circ} \mathrm{C}$ in order to initialize the polyesterification. Each prepared sol was then transferred into an alumina crucible (INCERAMICS S.A.) and put inside a furnace equipped with an EUROTHERM 906S temperature controller. The content was kept for about $24 \mathrm{~h}$ at $100{ }^{\circ} \mathrm{C}$ in order to evaporate the solvents $\left(\mathrm{H}_{2} \mathrm{O}-\mathrm{HNO}_{3}\right.$ azeotrope) and to complete the polyesterification. A yellowish, foamy-like viscous gel was obtained. The temperature was raised up to $350{ }^{\circ} \mathrm{C}$ for $3 \mathrm{~h}$ in order to remove the water residuals and dry the gel until it turned into black, brittle resin. To start the pyrolysis process and to get rid of the organic part, the temperature was gradually raised up to $500{ }^{\circ} \mathrm{C}$ and kept for $24 \mathrm{~h}$. After that, the temperature was increased to $650{ }^{\circ} \mathrm{C}$ and the process was still carried out for $48 \mathrm{~h}$. In between these stages and after their completion, the powder materials were thoroughly ground in an agate mortar. Such a long duration of the synthesis (including $72 \mathrm{~h}$ of pyrolysis) is required to ensure complete oxidation from $\mathrm{Te}^{4+}$ to $\mathrm{Te}^{6+}$. From the analytical point of view, the chemical reactions that take place between the initial reagents during the synthesis at a proper temperature and within a sufficient process time according to the Pechini method (for undoped BTBO) can be written by the following equations:

$$
\begin{aligned}
& \mathrm{Bi}_{2} \mathrm{O}_{3(s)}+\mathrm{TeO}_{2(s)} \stackrel{\mathrm{T}_{1}}{\longrightarrow} \mathrm{Bi}_{2} \mathrm{TeO}_{5(s)} \\
& \mathrm{Bi}_{2} \mathrm{TeO}_{5(s)}+\mathrm{TeO}_{2(s)}+\frac{1}{2} \mathrm{O}_{2(g)} \stackrel{\mathrm{T}_{2}}{\longrightarrow} \mathrm{Bi}_{2} \mathrm{Te}_{2} \mathrm{O}_{8(s)} \\
& \mathrm{Bi}_{2} \mathrm{Te}_{2} \mathrm{O}_{8(s)}+2 \mathrm{Bi}_{2} \mathrm{O}_{3(s)}+2 \mathrm{H}_{3} \mathrm{BO}_{3(s)} \\
& \quad+\frac{1}{2} \mathrm{O}_{2(g)} \stackrel{\mathrm{T}_{2}}{\longrightarrow} 2 \mathrm{Bi}_{3} \mathrm{TeBO} \mathrm{O}_{9(s)}+3 \mathrm{H}_{2} \mathrm{O}_{(g)} \uparrow \\
& 3 \mathrm{Bi}_{2} \mathrm{O}_{3(s)}+2 \mathrm{TeO}_{2(s)}+\mathrm{O}_{2(g)} \\
& \quad+2 \mathrm{H}_{3} \mathrm{BO}_{3(s)} \stackrel{\mathrm{T}_{1}, \mathrm{~T}_{2}}{\longrightarrow} 2 \mathrm{Bi}_{3} \mathrm{TeBO}_{9(s)}+3 \mathrm{H}_{2} \mathrm{O}_{(g)} \uparrow
\end{aligned}
$$

The sequence given above is the most probable, while BTBO is the only documented existing phase that consists of bismuth, tellurium and boron at the same time. Tellurium ions can be oxidized from +4 to +6 state (through the intermediate $\mathrm{Bi}_{2} \mathrm{Te}_{2} \mathrm{O}_{8}$ phase, containing a tellurium pair at both +4 and +6 states), thanks to the presence of oxygen/air atmosphere at high temperature. It explains such a long duration of this process. Even if reaction (1) can occur at $T_{1}$ (below $500{ }^{\circ} \mathrm{C}$ ), reactions (2) and (3) can run simultaneously, but only at a suitably high temperature $T_{2}$. Reaction (4) describes the summary reaction taking place in this process. One can see that the final product (BTBO) is formed as a result of redox reaction. In our study, $T_{1}$ was equal to $500{ }^{\circ} \mathrm{C}$ and $T_{2}$ was set to $650{ }^{\circ} \mathrm{C}$. After the reaction completion, the crucible was taken out of the furnace and rapidly cooled to room temperature. Its contents were crushed and ground in an agate mortar and very fine, almost colorless BTBO: $\mathrm{Nd}^{3+}$ powders were obtained. Synthesis procedure provided above makes it possible to determine and calculate the precise amounts of $\mathrm{Nd}_{2} \mathrm{O}_{3}$ and $\mathrm{Bi}_{2} \mathrm{O}_{3}$ one should use in the synthesis of each of the BTBO: $\mathrm{Nd}^{3+}$ systems (for 0.5, 
$1.0,2.5,5.0,7.5$ and 10.0 at. $\%$ of $\mathrm{Nd}^{3+}$ ). According to the literature data given for other borates, i.e. $\mathrm{Bi}_{2}$ $\mathrm{ZnOB}_{2} \mathrm{O}_{6}$ [8] or $\delta-\mathrm{BiB}_{3} \mathrm{O}_{6}$ [26], we assumed that it is possible to substitute effectively the $\mathrm{Bi}^{3+}$ with $\mathrm{Nd}^{3+}$ ions, what was later confirmed by XRD measurements. In this work, the $\mathrm{Nd}$ dopant concentration is expressed in at.\% of $\mathrm{Nd}^{3+}$ ions substituting $\mathrm{Bi}^{3+}$ ions, which is determined as $\mathrm{Nd}$ and $\mathrm{Bi}$ atoms content, relative to three $\mathrm{Bi}$ atoms in the structure unit of $\mathrm{Bi}_{3} \mathrm{TeBO}_{9}$ (Table 1).

On the basis of synthesis reaction stoichiometry (Reaction (4)) and mutual molar proportions, it can be calculated that $0.69894 \mathrm{~g}$ of $\mathrm{Bi}_{2} \mathrm{O}_{3}$ should be used for the synthesis of $1 \mathrm{mmol}$ of undoped $\mathrm{BTBO}$, while for the synthesis of the same amount of doped BTBO: $\mathrm{Nd}^{3+}$ with $\mathrm{Nd}^{3+}$ concentration equal to $5.0 \%$ at, it requires $0.66399 \mathrm{~g}$ of $\mathrm{Bi}_{2} \mathrm{O}_{3}$ and $0.02524 \mathrm{~g}$ of $\mathrm{Nd}_{2} \mathrm{O}_{3}$, respectively. These calculations show that the molar ratio of $\mathrm{Nd}^{3+}$ to $\mathrm{Bi}^{3+}$ ions in target BTBO: $\mathrm{Nd}^{3+}$ systems should be exactly the same as the molar ratio of used oxides: $\mathrm{Nd}_{2} \mathrm{O}_{3}$ and $\mathrm{Bi}_{2} \mathrm{O}_{3}$ in the initial mixture of needed reagents. Based on the above mentioned (and the information concerning the necessary excesses of Te and B), it is possible to determine the absolute masses of all reagents needed for the process.

\section{Characterization}

\section{Experimental methods}

The diffraction patterns of the synthesized BTBO: $\mathrm{Nd}^{3+}$ powders were collected using the BRUKER D8 Discover diffractometer equipped with the $\mathrm{CuK}_{\alpha}$ radiator $\left(\lambda_{K \alpha 1}=1.540598 \AA, \lambda_{K \alpha 2}=1.544426 \AA\right.$, Siemens KFL CU $2 \mathrm{~K}, 40 \mathrm{kV}$ voltage and $40 \mathrm{~mA}$ current in operating mode) and Göbel FGM2 mirror. The Bragg-Brentano diffraction geometry was applied. The diffraction angle $2 \theta_{B}$ ranged from 18 to $70^{\circ}$ with a step of $0.01^{\circ}$ and acquisition time of $2 \mathrm{~s}$ per step. All the measurements were carried out at $298 \mathrm{~K}$ in the temperature-stabilized Anton Paar HTK $1200 \mathrm{~N}$ chamber. For data processing, the
DIFFRAC.SUITE EVA application was used, allowing the $\lambda_{K \alpha 2}$ signal component deconvolution and removal, background subtraction and data smoothing (using the fast Fourier transform). The phase analysis was made with the support of the Crystallography Open Database (COD). For crystallographic calculations, the FullPROF ver. 3.0 program was used. This application allowed the Rietveld refinement and calculation of the precise unit cell parameters according to the diffraction profile fitting.

The microscopic analysis of BTBO: $\mathrm{Nd}^{3+}$ powders was performed with the scanning electron microscope (SEM/FEI Quanta 250FEG). The samples were analyzed in the low vacuum mode at the pressure $70 \mathrm{~Pa}$. The images were recorded in secondary electron mode at an accelerating voltage of $5 \mathrm{kV}$. Energy dispersive X-ray (EDX) analysis was performed with the Edax Octane SDD system at an accelerating voltage of $30 \mathrm{kV}$.

The Raman investigations were performed in the back-scattering geometry using the Renishaw InVia Raman microscope equipped with the confocal the DM 2500 Leica optical microscope and the CCD detector. The unpolarized Raman spectra were excited with the Ar laser emitting light of $488 \mathrm{~nm}$ wavelength and recorded in single scan with $30 \mathrm{~s}$ exposure time and $1 \mathrm{~mW}$ of the applied power. The position of the Raman peaks was calibrated before data collection using the Si reference sample as an internal standard with the peak position at $520.3 \mathrm{~cm}^{-1}$. The diffraction-limited optical spatial resolution depended on the excitation wavelength and for the used $50 \times$ LWD objective it was approximately equal to $1.5 \mu \mathrm{m}$. The instrumental resolution of the spectrometer was better than $2 \mathrm{~cm}^{-1}$. Spectral analysis was performed with the software packages WiRE3.1/Renishaw.

The reflectance spectra were measured with the Varian Model 5E UV-VIS-NIR spectrophotometer equipped with two excitation sources: the tungsten halide lamp in NIR/VIS and the deuterium arc UV range. As detectors were used the Hamamatsu R928 PMT in UV/VIS and Peltier-cooled PbS photocell in NIR range. All spectra were corrected for sources,
Table 1 The Nd and Bi content of the series of investigated BTBO: $\mathrm{Nd}^{3+}$ samples

\begin{tabular}{lllllll}
\hline BTBO: $\mathrm{Nd}^{3+}$ & 0.5 at. $\%$ & 1.0 at. $\%$ & 2.5 at. $\%$ & 5.0 at. $\%$ & 7.5 at. $\%$ & 10.0 at.\% \\
\hline $\mathrm{Nd}$ & 0.015 & 0.030 & 0.075 & 0.150 & 0.225 & 0.300 \\
$\mathrm{Bi}$ & 2.985 & 2.970 & 2.925 & 2.850 & 2.775 & 2.700 \\
\hline
\end{tabular}


detectors and gratings characteristics. The excitation and emission spectra as well as decay kinetics and quantum yield measurements of BTBO: $\mathrm{Nd}^{3+}$ crystalline powders were recorded using the FLS980 Fluorescence Spectrometer (Edinburgh Instruments) equipped with the holographic grating of 1800 lines / $\mathrm{mm}$, blazed at $300 \mathrm{~mm}$ focal length monochromators in Czerny Turner configuration. The excitation and emission spectra were obtained using a $450 \mathrm{~W}$ Xenon lamp. For decay times measurements, the $450 \mathrm{~W}$ excitation source was replaced with the $150 \mathrm{~W}$ lamp $(\mu \mathrm{F} 2)$ with external triggering. The emission spectra and decay times in the visible range were recorded on the Hammamatsu C5680 streak camera with time resolution below 50 ps and effective spectral range from 200 to $1000 \mathrm{~nm}$. An excitation source was the Coherent Libra-S-laser (femtosecond laser, wavelength $800 \mathrm{~nm}$, pulse width of less than $100 \mathrm{fs}$ and energy of $1 \mathrm{~mJ}$ at $1 \mathrm{kHz}$ repetition rate) paired with the Coherent OPerA Solo Optical Parametric Oscillator (two-stage amplifier of white continuum) that allows generation of pulses in the range of wavelengths from 230 to $2800 \mathrm{~nm}$.

\section{Results and discussion}

\section{Crystal structure}

BTBO crystalizes in hexagonal structure of $P 6_{3}$ space group with two formula units in the unit cell. The unit-cell parameters of BTBO crystal are: $a=8.7510(12) \AA, c=5.8981(12) \AA$ and $\mathrm{V}=391.16 \AA^{3}$ [9]. The crystal structure of BTBO is formed by two covalently bonded ionic complexes, octahedral $\mathrm{TeO}_{6}{ }^{6-}$ and trigonal-planar $\mathrm{BO}_{3}{ }^{3-}$ groups. In particular, $\mathrm{B}$ atoms are surrounded by three $\mathrm{O}$ atoms to form the trigonal-planar $\mathrm{BO}_{3}$ groups with uniform $\mathrm{B}-\mathrm{O}$ bond lengths, while $\mathrm{Te}^{6+}$ cations are coordinated by six $\mathrm{O}$ atoms with different $\mathrm{Te}-\mathrm{O}$ bond lengths. (The $\mathrm{TeO}_{6}$ octahedra are slightly deformed from the regular octahedral configuration.) Owing to the size similarity of the ionic radii of the $\mathrm{Nd}^{3+}$ and $\mathrm{Bi}^{3+}$ ions, in the doped BTBO microcrystals, $\mathrm{Bi}^{3+}$ ions can be efficiently substituted by $\mathrm{Nd}^{3+}$ ions. In the crystal structure of $\mathrm{BTBO}$, the $\mathrm{BO}_{3}$ layers are alternate with the cationic layers made of $\mathrm{TeO}_{6}$ octahedra and $\mathrm{Bi}^{3+}$ ions along the $z$-axis. The $\mathrm{BO}_{3}$ triangles are

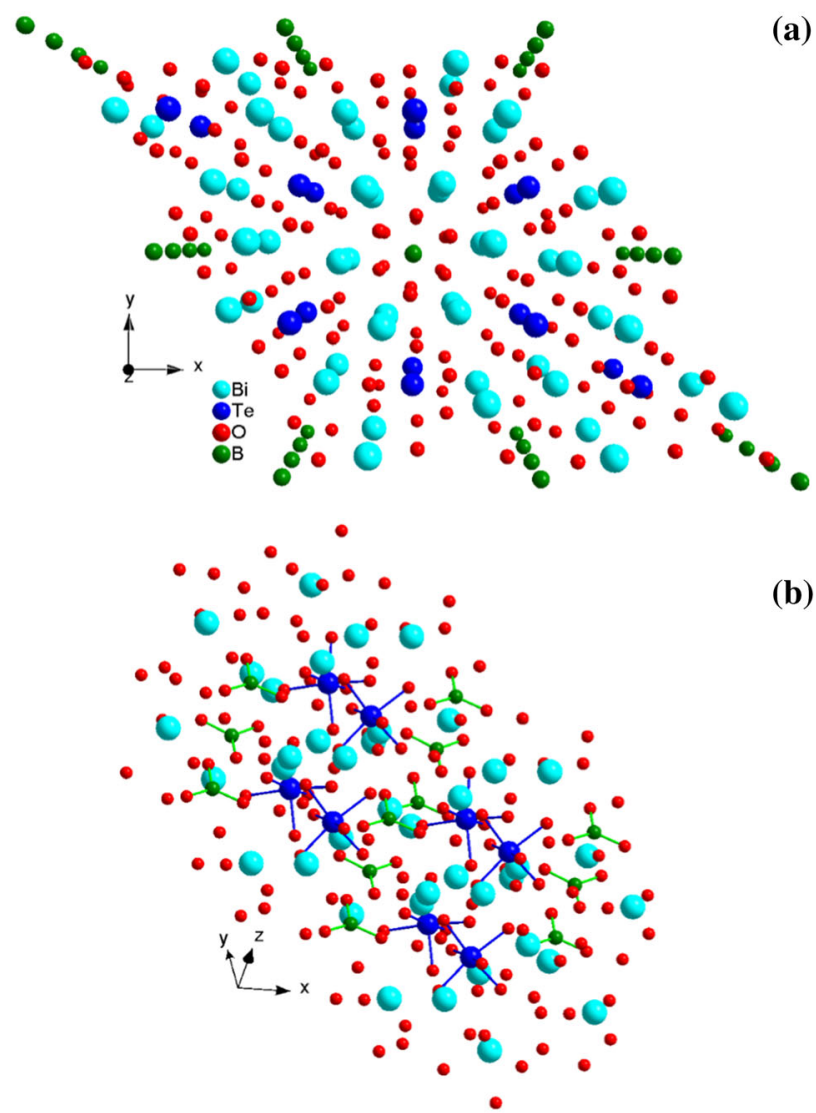

Figure 1 Structure of BTBO crystal (a) a view along the $c$ axis (b) structure projection according to the $x y z$ orientation [27].

placed in staggered arrangement along the $z$ direction. Moreover, the $\mathrm{BO}_{3}$ and $\mathrm{TeO}_{6}$ groups are arranged similarly along the $x$ and $y$ axis, creating the alternate rows of $\mathrm{BO}_{3}$ and $\mathrm{TeO}_{6}$ groups (Fig. 1) $[10,13]$. The structure of BTBO crystal presented in Fig. 1 was prepared based on the structure data involved in the Ref. [9]. The reference system (xyz) was defined by the following convention: $x$ is parallel to $a, y$ is perpendicular to $a$ and $z$ is parallel to $c$ and perpendicular to the $x y$ plane. In the used notation, $a$ and $c$ denote the crystallographic axes of the hexagonal system.

In particular, Fig. 1a presents the perspective view of BTBO structure along the $c$ axis with the following coordination of $\mathrm{B}, \mathrm{Te}$ and $\mathrm{Bi}$ atoms: $(0,0,0.425(3))$, $(2 / 3,1 / 3,0.0813(2))$ and (0.29827(3), 0.34622(3), $0.10689(12))$, respectively [9]. In Fig. 1b, the structure projection according to the $x y z$ orientation with some planar $\mathrm{BO}_{3}$ groups and $\mathrm{TeO}_{6}$ octahedra is presented. Moreover, we have already presented the detailed 


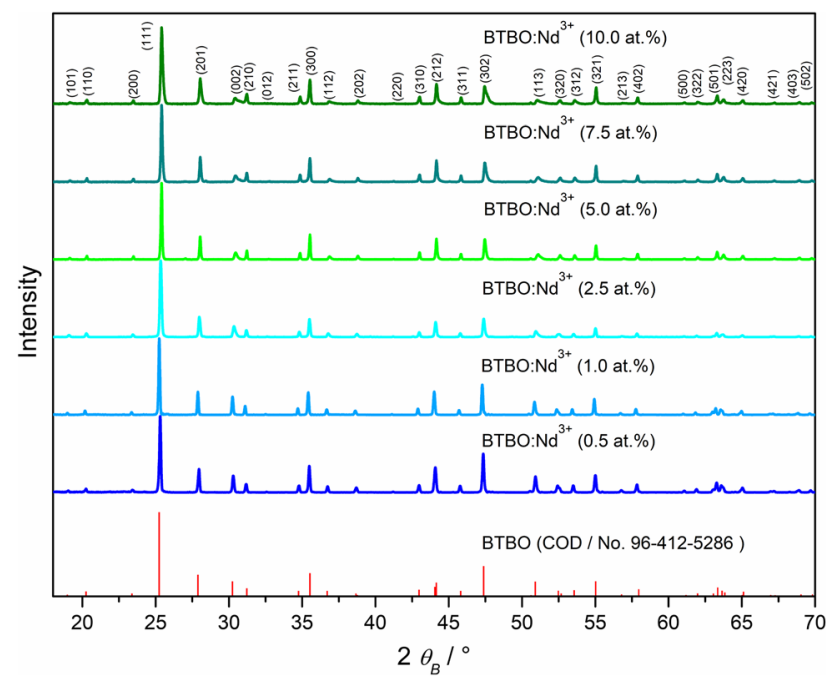

Figure 2 A set of experimental powder XRD patterns of BTBO: $\mathrm{Nd}^{3+}$ samples.

description of BTBO structure in our previous paper [13].

The results of diffraction measurements of BTBO: $\mathrm{Nd}^{3+}$ powders are presented in Fig. 2. All presented diffraction patterns of the synthesized BTBO: $\mathrm{Nd}^{3+}$ are in good agreement with the reference COD card (No. 96-412-5286), what means that all of them represent hexagonal class with $P 6_{3}$ (173) space group $(Z=2)$. No diffraction lines originating from impurities, side products or unreacted reagents are observed, what indicates that BTBO: $\mathrm{Nd}^{3+}$ is the only reaction product. The reference Crystallographic Information File (CIF) of BTBO phase used for Rietveld refinement was received from the supplementary data given in Ref. [9]. The results for BTBO: $\mathrm{Nd}^{3+}$ compounds show that the original symmetry group of the crystal remains undisturbed when the $\mathrm{Nd}^{3+}$ ions are incorporated into the BTBO matrix.
The unit cell parameters of each synthesized sample are presented in Table 1 . The values of effective ionic radius of $\mathrm{Bi}^{3+}$ and $\mathrm{Nd}^{3+}$ are equal to 1.03 and $0.983 \AA$, respectively [28]. Smaller $\mathrm{Nd}^{3+}$ ions radius can suggest that isovalent substitution of $\mathrm{Bi}^{3+}$ ions with $\mathrm{Nd}^{3+}$ should lead to progressive decrease in the BTBO: $\mathrm{Nd}^{3+}$ unit cell volume.

The results in Table 2 reveal irregular changes in the BTBO: $\mathrm{Nd}^{3+}$ unit cell parameters and its volume vs. the content of $\mathrm{Nd}^{3+}$ ions. In particular, the lattice constant $a$ increases with increasing $\mathrm{Nd}^{3+}$ content up to 5.0 at. $\% \mathrm{Nd}^{3+}$ ions in BTBO: $\mathrm{Nd}^{3+}$ and then decreases, while $c$ shows a distinguished decrease with increasing $\mathrm{Nd}^{3+}$ content. It is also seen that the only factor that increases progressively with $\mathrm{Nd}^{3+}$ content is the $a / c$ ratio, and at around 10 at. $\% \mathrm{Nd}^{3+}$ it stabilizes, as shown in Table 2. It may suggest that the geometry of BTBO: $\mathrm{Nd}^{3+}$ unit cell is slightly changing (with unchanged symmetry class) and can affect its non-centrosymmetry. Different character of the courses of changes in the lattice constants $a$ and $c$ can be explained by the anisotropic behavior of these structure parameters and various distribution of $\mathrm{Nd}^{3+}$ dopant in the BTBO: $\mathrm{Nd}^{3+}$ microcrystals on the surface and the volume of the grains, depending on the $\mathrm{Nd}^{3+}$ concentration. The threshold $\mathrm{Nd}^{3+}$ concentration in BTBO: $\mathrm{Nd}^{3+}$ from which this volume compression starts is ca. 2.5 at. $\% \mathrm{Nd}^{3+}$ ions. In particular, due to microscale of investigated polycrystalline materials, the distribution of $\mathrm{Nd}^{3+}$ dopant may vary within a single grain and a significant increase in their effective surface area takes place. As a result, the $\mathrm{Nd}^{3+}$ dopant may more preferably concentrate closer to the surface of the BTBO: $\mathrm{Nd}^{3+}$ microcrystals and then it is more bound to its surface than in its volume. Especially, when the concentration of $\mathrm{Nd}^{3+}$ ions is low, it may more readily build up
Table 2 Calculated unit cell parameters of BTBO: $\mathrm{Nd}^{3+}$ powders

\begin{tabular}{lllll}
\hline Compound & \multicolumn{2}{l}{ Unit cell parameters $[\AA]$} & \multirow{2}{l}{$\mathrm{V} / \AA^{3}$} \\
\cline { 2 - 4 } & $A$ & \multicolumn{1}{l}{$\mathrm{c}$} & \\
\hline BTBO [9] & $8.7510(12)$ & $5.8981(12)$ & 1.4837 & 391.16 \\
BTBO [13] & $8.7505(2)$ & $5.8871(2)$ & 1.4864 & 390.39 \\
BTBO: $\mathrm{Nd}^{3+}(0.5$ at.\%) & $8.7483(2)$ & $5.8879(2)$ & 1.4858 & 390.25 \\
BTBO: $\mathrm{Nd}^{3+}(1.0$ at.\%) & $8.7520(1)$ & $5.8877(1)$ & 1.4865 & 390.56 \\
BTBO: $\mathrm{Nd}^{3+}(2.5$ at.\%) & $8.7570(3)$ & $5.8855(4)$ & 1.4879 & 390.86 \\
BTBO: $\mathrm{Nd}^{3+}(5.0$ at.\%) & $8.7592(1)$ & $5.8716(2)$ & 1.4918 & 390.12 \\
BTBO: $\mathrm{Nd}^{3+}(7.5$ at.\%) & $8.7544(2)$ & $5.8639(2)$ & 1.4929 & 389.20 \\
BTBO: $: \mathrm{Nd}^{3+}(10.0$ at.\%) & $8.7523(3)$ & $5.8618(3)$ & 1.4931 & 388.87 \\
\hline
\end{tabular}


in the near-surface regions. Then, despite maintaining the parental BTBO (hexagonal) structure, the local strains in the crystal lattice may occur, which will result in an increase in the lattice constants and volume of the BTBO: $\mathrm{Nd}^{3+}$ unit cell. On the other hand, as the concentration of the $\mathrm{Nd}^{3+}$ dopant increases, the possibility of filling the near-surface regions with it begins to decrease, which in turn necessitates the need for further incorporation of the dopant into the BTBO: $\mathrm{Nd}^{3+}$ microcrystals volume. Then, the changes in geometry of the BTBO: $\mathrm{Nd}^{3+}$ cell are closer to those predicted theoretically, showing progressive compression of BTBO. Moreover, for BTBO samples with higher $\mathrm{Nd}^{3+}$ concentrations (5.0, 7.5 and 10.0 at.\%), we observed decreasing unit cell volume as a result of the smaller $\mathrm{Nd}^{3+}$ ionic radius (substituting ions) in comparison with the substituted $\mathrm{Bi}^{3+}$ ions. As a result, $\mathrm{Nd}^{3+}-\mathrm{Nd}^{3+}$ distances are shortened with increasing $\mathrm{Nd}^{3+}$ concertation in BTBO matrix. This effect can consequently lead to LCQ and different character of luminescence decay time of excited $\mathrm{Nd}^{3+}$ ions for samples doped with 5.0, 7.5 and 10.0 at.\% of $\mathrm{Nd}^{3+}$ ions.

\section{SEM and EDX analysis}

Microscopic observation of the BTBO: $\mathrm{Nd}^{3+}$ samples revealed their morphology. All the materials discussed had different irregular microstructures (Fig. 3).

The sample BTBO: $\mathrm{Nd}^{3+}(0.5$ at.\%) (Fig. 3a) has both large grains from 7 to 15 microns in size and smaller grains between 3 and 5 microns in size. The large grains are often agglomerations of much smaller ones, of up to a micrometer in size. However, large portions of the large grains are monolithic. The sample BTBO: $\mathrm{Nd}^{3+}(1.0$ at.\%) (Fig. 3b) has a very similar microstructure to that previously described. The only significant difference is that the sizes of the largest agglomerates reach 30 microns. The sample BTBO: $\mathrm{Nd}^{3+}(2.5$ at.\%) (Fig. 3c) has a similar microstructure. Compared to previous ones, there are no such large agglomerates made of small grains, and the largest observed grains are monolithic. Their diameters are between 7 and 14 microns. The sizes of small, non-aggregating grains are mostly between 0.5 and 2.5 microns. From among all analyzed samples, BTBO: $\mathrm{Nd}^{3+}(5.0$ at.\%) (Fig. 3d) has the morphology most closely resembling large crystals with clearly visible faces. The sizes of their edges are from 2 to $8 \mu \mathrm{m}$. For BTBO: $\mathrm{Nd}^{3+}$ (7.5 at.\%) (Fig. 3e), we observe the largest grains with the size of tens of micrometers with a small amount of grains with the size of $1-2 \mu \mathrm{m}$. Increase in the $\mathrm{Nd}^{3+}$ content to 10.0 at $\%$ (Fig. 3f) resulted in a reduction of the grains size to $1-4 \mu \mathrm{m}$ and a change in their edges that became strongly curved. However, their crystalline nature can be observed, but is less visible than for the sample in Fig. 3d. Moreover, in the SEM images Fig. 3a-f of all samples, the nano-sized crystals can be also observed.

The EDX analysis of investigated samples allows to determine the elements content for BTBO: $\mathrm{Nd}^{3+}$ systems. In Fig. 4, the EDX spectrum for the selected BTBO: $\mathrm{Nd}^{3+}$ (10.0 at.\%) sample is presented.

Selected scanned areas of the sizes $28 \times 36 \mu \mathrm{m}^{2}$ of all investigated samples were subjected to the EDX analysis. It should be noted that due to inhomogeneous morphology of the investigated samples, the EDX analysis of $\mathrm{Nd}$ atoms used at a low content, provides very local information. Moreover, the EDX
Figure 3 SEM micrographs of BTBO: $\mathrm{Nd}^{3+}(0.5$ at.\%) (a), BTBO: $\mathrm{Nd}^{3+}(1.0$ at.\%) (b), BTBO: $\mathrm{Nd}^{3+}(2.5$ at.\%) (c), BTBO: $\mathrm{Nd}^{3+}(5.0$ at.\%) (d), BTBO: $\mathrm{Nd}^{3+}(7.5$ at.\%) (e) and BTBO: $\mathrm{Nd}^{3+}(10.0$ at.\%) (f) in magnification of $30000 x$.
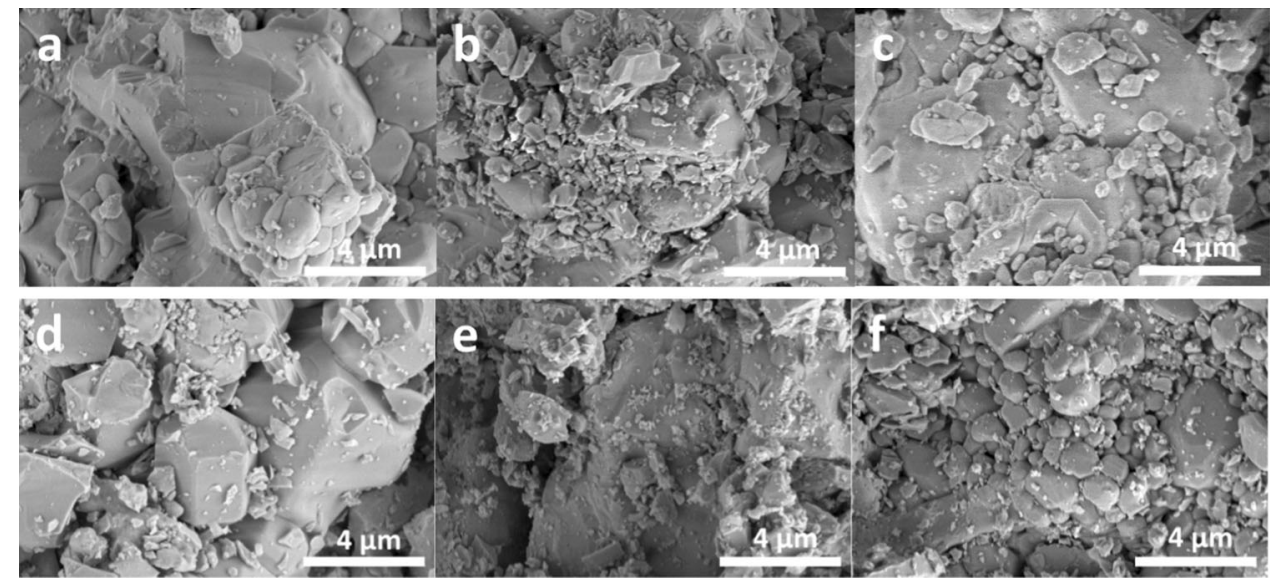
Figure 4 The EDX spectrum for BTBO: $\mathrm{Nd}^{3+}$ (10.0 at.\%) sample.

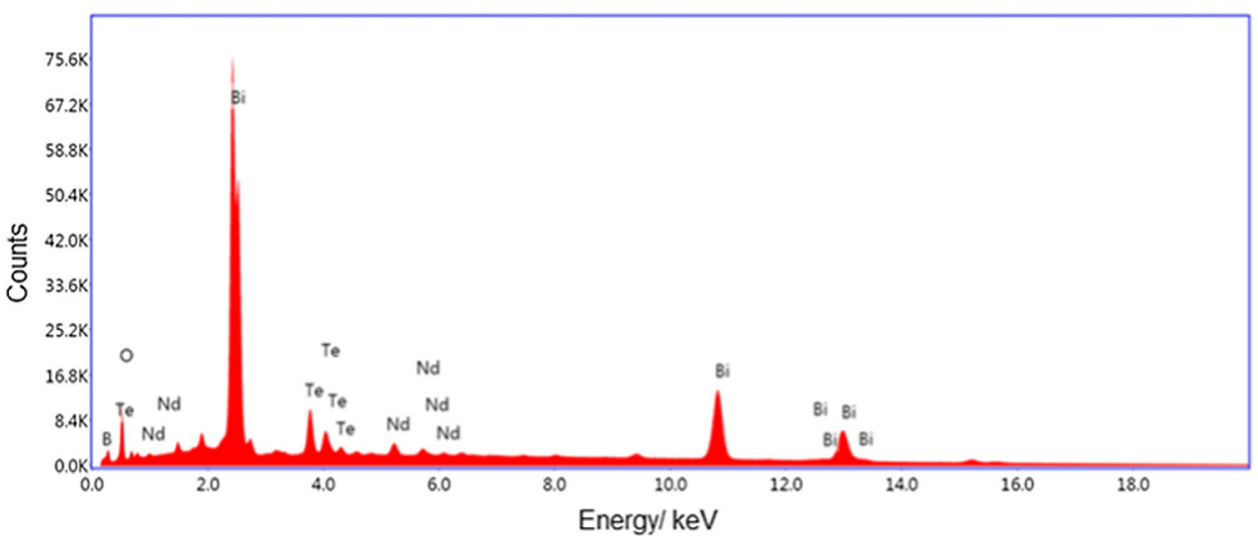

Table 3 The elements content in BTBO: $\mathrm{Nd}^{3+}(10.0$ at.\%) sample

\begin{tabular}{lllll}
\hline BTBO: $\mathrm{Nd}^{3+}(10.0$ at.\% $)$ & Element & Weight $\%$ & Atomic $\%$ & Error \% \\
\hline & B & 8.26 & 37.85 & 4.63 \\
& O & 13.42 & 41.55 & 9.31 \\
& Te & 11.26 & 4.37 & 5.32 \\
& Nd & 3.08 & 1.06 & 6.89 \\
& Bi & 63.98 & 15.17 & 2.61 \\
\hline
\end{tabular}

measurement of elements present at very low concentrations is charged with a relatively large uncertainty. The weight and atomic content of particular elements (relative to the structure unit $\mathrm{Bi}_{3} \mathrm{TeBO}_{9}$ ) in a selected exemplary BTBO: $\mathrm{Nd}^{3+}(10.0$ at.\%) sample are given in Table 3.

The theoretically calculated content of $\mathrm{Nd}$ and $\mathrm{Bi}$ atoms, relative to all atoms in the structure unit of $\mathrm{Bi}_{3} \mathrm{TeBO}_{9}$ (three $\mathrm{Bi}$ atoms, one Te atom, one $\mathrm{B}$ atom and nine $\mathrm{O}$ atoms) and the experimentally measured content of $\mathrm{Nd}$ atoms (on the basis of EDX data) for the series of investigated samples are given in Table 4.

As seen from Table 4, the Nd content in the studied samples increases with increasing concentration from 0.5 to 10 at.\%, both for theoretical as well as experimental values, as expected. The same $\mathrm{Nd}$ content observed for experimental value for 7.5 and 10.0 at.\% may be results on the measured data mostly from the surface than from volume of microcrystals. As already mentioned, the volume in comparison with surface location of $\mathrm{Nd}^{3+}$ ions are more preferred in higher $\mathrm{Nd}^{3+}$ doped samples.

\section{$\mu$-Raman investigation}

BTBO crystalizes in hexagonal structure with $\mathrm{P}_{3}$ space group. The primitive unit cell of BTBO crystal comprises two formula units and contains 28 atoms engaged in 84 fundamental vibrations. The zonecenter optic modes predicted from the group theory analysis for BTBO crystals can be classified according to the following formula: $14 \mathrm{~A}+14 \mathrm{~B}+14 \mathrm{E}_{1}+14 \mathrm{E}_{2}$. The phonon modes of $\mathrm{A}, \mathrm{E}_{1}$ and $\mathrm{E}_{2}$ types are Raman active, whereas the modes of $A$ and $E_{1}$ species are IR
Table 4 The theoretical and experimental contents of $\mathrm{Nd}$ atoms with the estimated absolute uncertainty for the series of BTBO: $\mathrm{Nd}^{3+}$ samples

\begin{tabular}{llc}
\hline \multirow{2}{*}{ Compound } & \multicolumn{2}{l}{ Content of Nd atoms in the structure unit } \\
\cline { 2 - 3 } & Theoretical value & Experimental value \\
\hline BTBO: $\mathrm{Nd}^{3+}(0.5$ at. $\%)$ & 0.107 & $0.03 \pm 0.01$ \\
BTBO: $\mathrm{Nd}^{3+}(1.0$ at. $\%)$ & 0.214 & $0.12 \pm 0.01$ \\
BTBO: $\mathrm{Nd}^{3+}(2.5$ at. $\%)$ & 0.536 & $0.23 \pm 0.02$ \\
BTBO: $\mathrm{Nd}^{3+}(5.0$ at. $\%)$ & 1.071 & $0.52 \pm 0.05$ \\
BTBO: $\mathrm{Nd}^{3+}(7.5$ at. $\%)$ & 1.607 & $1.06 \pm 0.08$ \\
BTBO: $\mathrm{Nd}^{3+}(10.0$ at. $\%)$ & 2.143 & $1.06 \pm 0.07$
\end{tabular}


active. The modes of B symmetry are inactive both in the Raman and IR spectra [13, 29, 30]. The BTBO structure is formed by octahedral $\mathrm{TeO}_{6}$ and trigonalplanar $\mathrm{BO}_{3}$ molecular groups, which have their own characteristic internal vibrations. In the ideal, isolated octahedra $\mathrm{TeO}_{6}$ unit with point group symmetry $\mathrm{O}_{\mathrm{h}}$, the internal vibrations can be classified into six fundamental modes: three Raman-active-the symmetric stretching vibrations $v_{1}\left(\sim 700 \mathrm{~cm}^{-1}\right)$, doubly degenerate asymmetric bending vibrations $v_{2}$ $\left(500-650 \mathrm{~cm}^{-1}\right)$ and triply degenerate symmetric bending $v_{5}$ modes (below $400 \mathrm{~cm}^{-1}$ ); two IR-active modes - the triply degenerate asymmetric bending vibrations $v_{3} \quad\left(500-650 \mathrm{~cm}^{-1}\right)$, triply degenerate asymmetric bending vibrations $v_{4}\left(400-500 \mathrm{~cm}^{-1}\right)$ and one $v_{6}$ internal mode inactive both in the Raman and IR spectra [31]. The triangular planar $\mathrm{BO}_{3}$ groups with $D_{3 h}$ symmetry have their four characteristic internal vibrations named: $\mu_{1} \mu_{2}, \mu_{3}, \mu_{4}$. Some of them are Raman-active $\left(\mu_{1}, \mu_{3}, \mu_{4}\right)$ and/or IR-active modes $\left(\mu_{2}, \mu_{3}, \mu_{4}\right)$. The vibrations of an ideal, isolated $\mathrm{BO}_{3}$ group can be classified into four fundamental modes: symmetric stretching mode $\mu_{1}\left(\sim 950 \mathrm{~cm}^{-1}\right)$, doubly degenerate asymmetric stretching mode $\mu_{3}$ (1250-1400 $\left.\mathrm{cm}^{-1}\right)$, doubly degenerate planar bending mode $\mu_{4}\left(\sim 600 \mathrm{~cm}^{-1}\right)$ and infrared active out-ofplane bending mode $\mu_{2}\left(700-800 \mathrm{~cm}^{-1}\right)[13,32,33]$. Moreover, the frequencies of external lattice vibrations (translations or librations of $\mathrm{Bi}(\mathrm{Nd})$ or Te atoms and $\mathrm{BO}_{3}$ and $\mathrm{TeO}_{6}$ groups) are located below $\sim 350 \mathrm{~cm}^{-1}$.

The unpolarized Raman spectra of undoped BTBO and BTBO: $\mathrm{Nd}^{3+}$ crystalline powders were recorded in the $100-1500 \mathrm{~cm}^{-1}$ spectral range at room temperature (Fig. 5).

The spectroscopic parameters of all Raman-active bands were analyzed by the fitting procedure using the Lorentzian-like function. The detailed assignment of all Raman-active bands and their determined wavenumbers values are presented in Table S1.

As follows from Fig. 5, Table S1 and the data given for undoped BTBO powder presented in our previous paper [13], the bands from the spectral range $1500-600 \mathrm{~cm}^{-1}$ were assigned to the stretching vibrations of $\mathrm{BO}_{3}$ groups or $\mathrm{TeO}_{6}$ octahedra. The medium intensity bands at 1297, 1283, 1262, $1241 \mathrm{~cm}^{-1}$ and weak bands at $1221 \mathrm{~cm}^{-1}$ were assigned to the stretching modes of $\mathrm{BO}_{3}$ units. The very weak Raman band at $1384 \mathrm{~cm}^{-1}$ is probably a result of higher order Raman scattering (according to

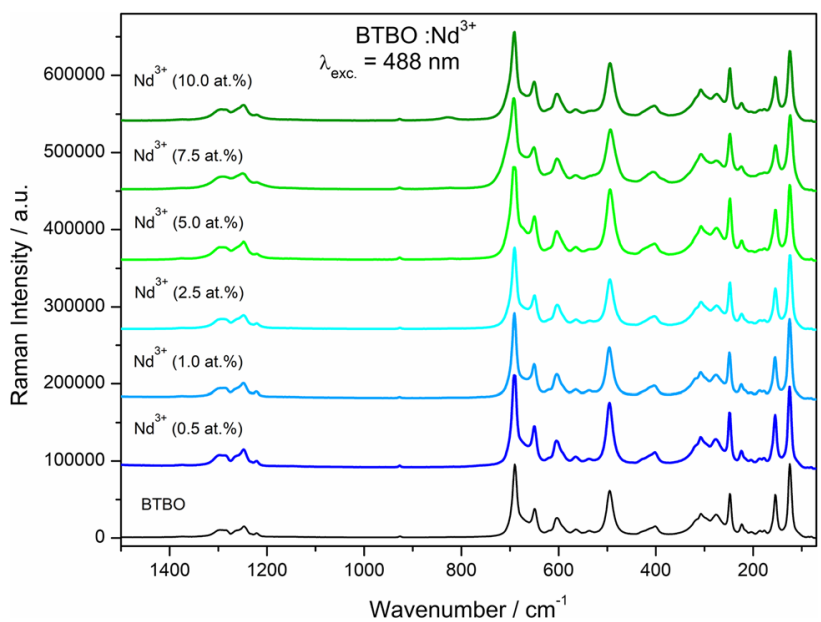

Figure 5 Unpolarized Raman spectra of undoped BTBO and BTBO: $\mathrm{Nd}^{3+}$ powders, detected at $300 \mathrm{~K}$.

our ab initio calculations) [13]. The very weak intensity modes detected at $926 \mathrm{~cm}^{-1}$ originate from A type $\mu_{1}$ internal stretching vibration of $\mathrm{BO}_{3}$ complex. The modes in the spectral rage $690-350 \mathrm{~cm}^{-1}$ correspond to the vibrations of $\mathrm{BO}_{3}$ and $\mathrm{TeO}_{6}$ groups. Many bands in this spectral range have the mixed character. The bands detected in the Raman spectra in the spectral region $690-600 \mathrm{~cm}^{-1}$ originate from the stretching vibrations $\mu_{4}$ and $\mu_{2}$ of $\mathrm{BO}_{3}$ or $v_{3}$ and $v_{1}$ of $\mathrm{TeO}_{6}$ groups. In particular, the most intensive modes recorded in this spectral range at $691 \mathrm{~cm}^{-1}$ and the medium modes occurring at $649 \mathrm{~cm}^{-1}$ were assigned to the $v_{1}$ and $v_{3}$ stretching vibrations of $\mathrm{TeO}_{6}$ groups, respectively. The weak modes at $620 \mathrm{~cm}^{-1}$, the medium modes at $604 \mathrm{~cm}^{-1}$ and the weak modes at $564 \mathrm{~cm}^{-1}$ detected in the spectra were attributed to the $\mu_{4}$ bending vibrations of $\mathrm{BO}_{3}$ groups. The other bands in the Raman spectra in the considered spectral range of $660-350 \mathrm{~cm}^{-1}$ were assigned to the vibrations of $\mathrm{TeO}_{6}$ octahedra. In particular, the shoulder at $596 \mathrm{~cm}^{-1}$ and the weak mode at $537 \mathrm{~cm}^{-1}$ detected in the spectra can be assigned to the bending $v_{2}$ vibrations; the very strong modes centered at $497 \mathrm{~cm}^{-1}$ and a shoulder at $414 \mathrm{~cm}^{-1}$ arise from the $v_{4}$ vibrations; the medium-intensity modes at $401 \mathrm{~cm}^{-1}$ in the spectra were assigned to the $v_{5}$ vibrations. According to the analysis of the calculated eigenvectors, the lowest frequency part of the spectrum, below $\sim 350 \mathrm{~cm}^{-1}$, originates from the external lattice vibrations of $\mathrm{Bi}(\mathrm{Nd})$ or $\mathrm{Te}$ atoms and $\mathrm{TeO}_{6}$ and $\mathrm{BO}_{3}$ complexes, as the rigid units, and mainly corresponds to the librational or translational motions of these molecular groups. In particular, the 
highest intensity modes in this range were centered at 124 and $154 \mathrm{~cm}^{-1}$ in the spectra. The low wavenumber/energy phonons detected in the Raman spectra in the range below $\sim 360 \mathrm{~cm}^{-1}$ are of mixed type and are related to the relatively large atomic masses of $\mathrm{Bi}$ and $\mathrm{Te}$ atoms [8]. All above-given wavenumbers were determined for BTBO: $\mathrm{Nd}^{3+}(0.5$ at.\%) sample. Moreover, the spectral analysis of the Raman spectra of undoped and $\mathrm{Nd}^{3+}$-doped BTBO powders allows to conclude that low $\mathrm{Nd}^{3+}$ concentrations used in this study do not influence on vibrational properties of BTBO matrix. The results of Raman scattering method show the low phonon energy of BTBO matrix, which is important in phonon-assisted energy transfer processes between active $\mathrm{Bi}^{3+}$ and $\mathrm{Nd}^{3+}$ ions.

\section{Luminescence}

All the bands present in the reflectance, excitation and absorption spectra, assigned to the energy levels of active $\mathrm{Nd}^{3+}$ ions, were identify on the basis of the Dieke's diagram [33].

The reflectance spectra of undoped BTBO and BTBO: $\mathrm{Nd}^{3+}$ powders detected in $250-1000 \mathrm{~nm}$ spectral range at $300 \mathrm{~K}$ are presented in Fig. 6.

In the reflectance spectra of BTBO: $\mathrm{Nd}^{3+}$ powders it can be observed the $f-f$ transitions from $\mathrm{Nd}^{3+}$ ions as well as band assigned to the transition from $\mathrm{Bi}^{3+}$ ions. The broad bands recorded in the range $200-370 \mathrm{~nm}$, with the intensity maximum at about $330 \mathrm{~nm}$ arise from the ${ }^{1} \mathrm{~S}_{0} \rightarrow{ }^{3} \mathrm{P}_{1}$ transition of $\mathrm{Bi}^{3+}$ ions. All other bands detected in reflectance spectra are assigned to the $f-f$ transitions from $\mathrm{Nd}^{3+}$ ions. The bands at about

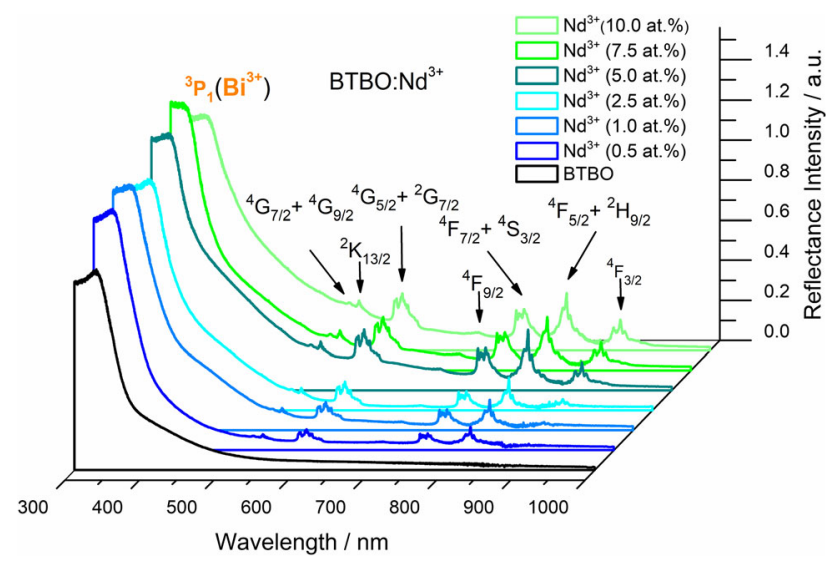

Figure 6 The reflectance spectra of undoped BTBO and BTBO: $\mathrm{Nd}^{3+}$ powders detected at $300 \mathrm{~K}$.
515 and $530 \mathrm{~nm}$ are related to the $\left({ }^{4} \mathrm{G}_{7 / 2}+{ }^{4} \mathrm{G}_{9 / 2}\right)$ $\rightarrow{ }^{4} \mathrm{I}_{9 / 2}$ and ${ }^{2} \mathrm{~K}_{13 / 2} \rightarrow{ }^{4} \mathrm{I}_{9 / 2}$ transitions, respectively. The most intensive peaks located in range $570-610 \mathrm{~nm}$ were assigned to the $\left({ }^{4} \mathrm{G}_{5 / 2}+{ }^{2} \mathrm{G}_{7 / 2}\right)$ $\rightarrow{ }^{4} \mathrm{I}_{9 / 2}$ transitions. The weak bands in the spectral range $670-700 \mathrm{~nm}$ correspond to the ${ }^{4} \mathrm{~F}_{9 / 2} \rightarrow{ }^{4} \mathrm{I}_{9 / 2}$ transitions. The bands in the spectral range $730-775 \mathrm{~nm}$ and $780-835 \mathrm{~nm}$ are present due to the $\left({ }^{4} \mathrm{~F}_{7 / 2}+{ }^{4} \mathrm{~S}_{3 / 2}\right) \rightarrow{ }^{4} \mathrm{I}_{9 / 2}$ and $\left({ }^{4} \mathrm{~F}_{5 / 2}+{ }^{2} \mathrm{H}_{9 / 2}\right) \rightarrow{ }^{4} \mathrm{I}_{9 / 2}$ transitions, respectively, and the peaks located in the spectral rage $850-890 \mathrm{~nm}$ are attributed to the ${ }^{4} \mathrm{~F}_{3 / 2}$ $\rightarrow{ }^{4} \mathrm{I}_{9 / 2}$ transitions.

The excitation spectra of BTBO: $\mathrm{Nd}^{3+}$ powders were recorded at $300 \mathrm{~K}$ in the spectral range 250-900 nm by monitoring the ${ }^{4} \mathrm{~F}_{3 / 2} \rightarrow{ }^{4} \mathrm{I}_{11 / 2}$ transition of $\mathrm{Nd}^{3+}$ ions at $1064 \mathrm{~nm}$ (Fig. 7).

As follows from Fig. 7, numerous bands were detected in the excitation spectra of BTBO: $\mathrm{Nd}^{3+}$ powders in the range from about $250 \mu \mathrm{m}$ to about $900 \mathrm{~nm}$. Moreover, the intensity of the bands in the spectra depends on $\mathrm{Nd}^{3+}$ concentration. The highest intensity excitation bands were detected in the spectrum of BTBO: $\mathrm{Nd}^{3+}$ powder doped with $\mathrm{Nd}^{3+}$ ions at the lowest concentration $(0.5$ at.\%). The corresponding bands in the excitation spectra of BTBO: $\mathrm{Nd}^{3+}$ powders were detected almost in the same positions for all $\mathrm{Nd}^{3+}$ concentrations. In particular, the bands recorded in the range $270-370 \mathrm{~nm}$ with the intensity maximum at about $330 \mathrm{~nm}$ arise from the ${ }^{4} \mathrm{D}_{3 / 2}$ $\leftarrow{ }^{4} \mathrm{I}_{9 / 2}$ transitions. Moreover, the broadening of the excitation bands in this spectral range results from the interference of the mentioned above $\mathrm{Nd}^{3+}$ excitation bands and the excitation bands assigned to the ${ }^{1} \mathrm{~S}_{0} \leftarrow{ }^{3} \mathrm{P}_{1}$ transition of $\mathrm{Bi}^{3+}$ ions. Very weak peaks at

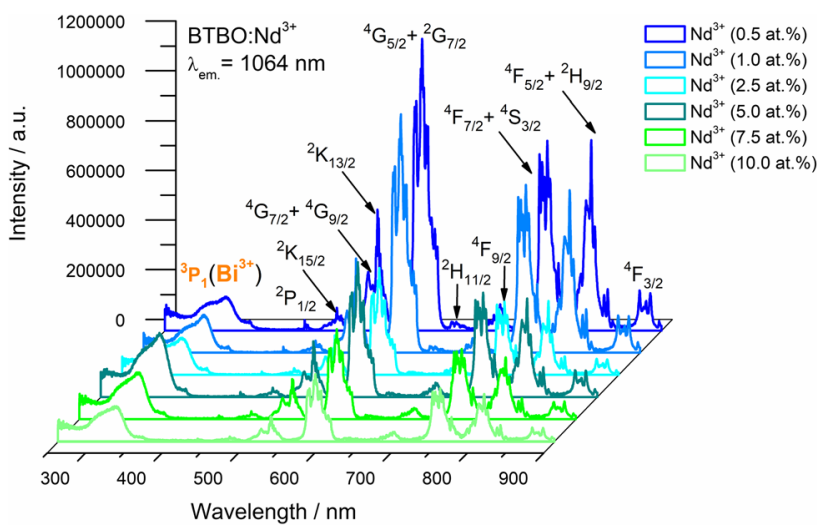

Figure 7 Excitation spectra of BTBO: $\mathrm{Nd}^{3+}$ powders recorded by monitoring the emission of the ${ }^{4} \mathrm{~F}_{3 / 2} \rightarrow{ }^{4} \mathrm{I}_{11 / 2}$ transition in $\mathrm{Nd}^{3+}$ ions at $1064 \mathrm{~nm}$, detected at $300 \mathrm{~K}$. 
about $430 \mathrm{~nm}$ correspond to the ${ }^{2} \mathrm{P}_{1 / 2} \leftarrow{ }^{4} \mathrm{I}_{9 / 2}$ transitions. The weak bands in the range from 450 to $490 \mathrm{~nm}$ can be assigned to the ${ }^{2} \mathrm{~K}_{15 / 2} \leftarrow{ }^{4} \mathrm{I}_{9 / 2}$ transitions. The strong bands at about $515 \mathrm{~nm}$ are related to the $\left({ }^{4} G_{7 / 2}+{ }^{4} G_{9 / 2}\right) \leftarrow{ }^{4} I_{9 / 2}$ transitions, while the strong peaks centered at about $530 \mathrm{~nm}$ arise from the ${ }^{2} \mathrm{~K}_{13 / 2} \leftarrow{ }^{4} \mathrm{I}_{9 / 2}$ transitions. The most intensive peaks located in range 570-610 $\mathrm{nm}$ were assigned to the $\left({ }^{4} G_{5 / 2}+{ }^{2} G_{7 / 2}\right) \leftarrow{ }^{4} I_{9 / 2}$ transitions. Moreover, the bands in the spectral range 620-640 nm (very weak) and $670-700 \mathrm{~nm}$ (weak) correspond to the ${ }^{2} \mathrm{H}_{11 / 2}$ $\leftarrow{ }^{4} \mathrm{I}_{9 / 2}$ and ${ }^{4} \mathrm{~F}_{9 / 2} \leftarrow{ }^{4} \mathrm{I}_{9 / 2}$ transitions, respectively. The very strong bands in the spectral range of $730-775 \mathrm{~nm}$ and $780-835 \mathrm{~nm}$ are due to the $\left({ }^{4} \mathrm{~F}_{7 / 2}\right.$ $\left.+{ }^{4} \mathrm{~S}_{3 / 2}\right) \leftarrow{ }^{4} \mathrm{I}_{9 / 2}$ and $\left({ }^{4} \mathrm{~F}_{5 / 2}+{ }^{2} \mathrm{H}_{9 / 2}\right) \leftarrow{ }^{4} \mathrm{I}_{9 / 2}$ transitions, respectively. The strong peaks located in the spectral rage $850-890 \mathrm{~nm}$ were attributed to the ${ }^{4} \mathrm{~F}_{3 / 2}$ $\leftarrow{ }^{4} \mathrm{I}_{9 / 2}$ transitions. It should be noted that the excitation spectra of BTBO:Nd ${ }^{3+}$ powders (Fig. 7) correspond well with the reflectance spectra (Fig. 6). However, the difference in the transitions intensity observed in the UV excitation and reflectance spectra is a result of different sensitivities of the detectors in the used equipment. It can be also observed that in NIR range, in which $\mathrm{PbS}$ detector is used with much lower sensitivity than R928 PMT, with decreasing $\mathrm{Nd}^{3+}$ concentration, the transition peaks intensity almost disappears. In the visible and UV range, the changes are less pronounced.

The emission spectra of BTBO: $\mathrm{Nd}^{3+}$ powders were investigated upon 327 and $586.4 \mathrm{~nm}$ excitation in the 800-1200 nm spectral range (Fig. 8).

The emission spectra of BTBO: $\mathrm{Nd}^{3+}$ powders show broad and intense bands in the range of $865-925 \mathrm{~nm}$ and $1035-1100 \mathrm{~nm}$. The broad multi-structure bands detected in the range of 865-925 $\mathrm{nm}$ are related to the ${ }^{4} \mathrm{~F}_{3 / 2} \rightarrow{ }^{4} \mathrm{I}_{9 / 2}$ transitions. The shape of these bands is a result of the Stark effect, which describes the shifting and splitting of spectral lines of active ions due to the presence of an external electric crystal field. As a result, the ${ }^{4} \mathrm{~F}_{3 / 2}$ energy level of $\mathrm{Nd}^{3+}$ splits into several Stark components [34]. The strong bands in the range $1035-1110 \mathrm{~nm}$ with a maximum at $1064 \mathrm{~nm}$ were attributed to the ${ }^{4} \mathrm{~F}_{3 / 2} \rightarrow{ }^{4} \mathrm{I}_{11 / 2}$ transitions. The shape of these bands also suggests the influence of the crystal field on the electronic level ${ }^{4} \mathrm{~F}_{3 / 2}$, which consists of Stark-levels, as mentioned above [35] Interestingly, the highest intensity emission bands in NIR upon the excitation in UV were detected in the spectra of BTBO: $\mathrm{Nd}^{3+}$ powders doped with the higher concentrations of $\mathrm{Nd}^{3+}$ ions (5. $0,7.5$ and 10 at.\%), with the maximum at 5.0 at.\% concentration (Fig. 8a). Upon the excitation in VIS, the highest intensity emission bands in NIR were detected in the spectra of BTBO: $\mathrm{Nd}^{3+}$ powders doped with the lower concentrations of $\mathrm{Nd}^{3+}$ ions $(0.5,1.0$ and 2.5 at.\%) with the maximum at 0.5 at.\% concentration (Fig. 8b). The observed phenomena result from the different energy transfer mechanisms upon the excitation in UV (by $\mathrm{Bi}^{3+}$ ions) and excitation in VIS spectral range (by $\mathrm{Nd}^{3+}$ ions).

In Fig. 9, the excitation and emission spectra registered in UV and VIS spectral range for undoped BTBO matrix are presented. In the excitation spectrum, only one band centered at about $327 \mathrm{~nm}$ assigned to the ${ }^{1} \mathrm{~S}_{0} \rightarrow{ }^{3} \mathrm{P}_{1}$ transition of $\mathrm{Bi}^{3+}$ ions was detected. It shows that $\mathrm{Bi}^{3+}$ ions present in BTBO
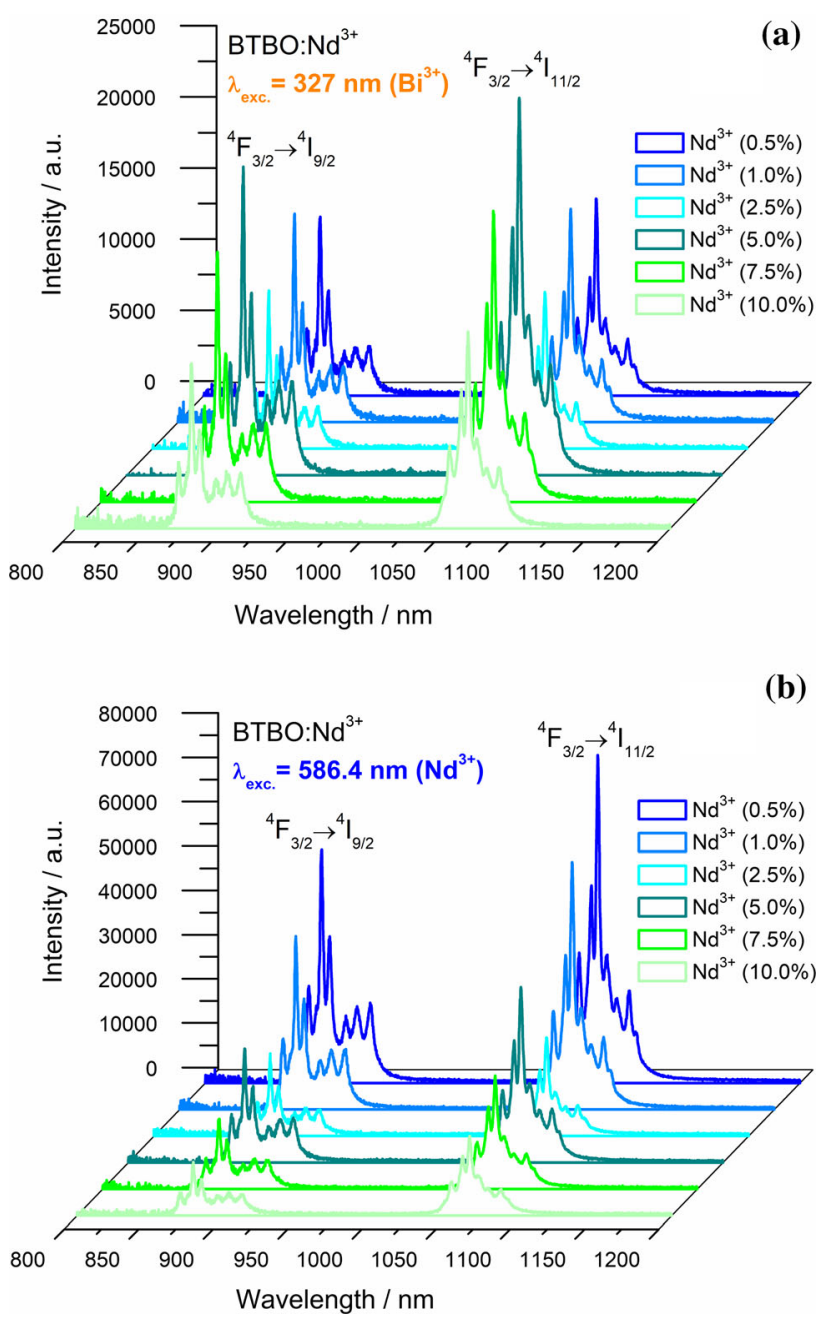

Figure 8 Emission spectra of BTBO: $\mathrm{Nd}^{3+}$ powders upon the excitation at $327 \mathrm{~nm}$ (a) and $586.4 \mathrm{~nm}$ (b), recorded at $300 \mathrm{~K}$. 
matrix can be used as a UV absorption sensitizer for $\mathrm{Nd}^{3+}$ ions in BTBO: $\mathrm{Nd}^{3+}$ samples. Moreover, the emission spectrum shows the broad emission band in the $450-650 \mathrm{~nm}$ with the maximum at $560 \mathrm{~nm}$ (yellow emission) related to the ${ }^{3} \mathrm{P}_{0} \rightarrow{ }^{1} \mathrm{~S}_{0}$ transition of $\mathrm{Bi}^{3+}$ ions.

The possible mechanisms of energy relaxation after UV or VIS excitation are illustrated schematically in Fig. 10.

Due to the close positions of electronic levels of the excited states of $\mathrm{Bi}^{3+}$ and $\mathrm{Nd}^{3+}$ ions, the energy transfer process from $\mathrm{Bi}^{3+}$ to $\mathrm{Nd}^{3+}$ ions is possible. In particular, after the excitation in UV (at $327 \mathrm{~nm}$ ), $\mathrm{Bi}^{3+}$ ions are excited from the ${ }^{1} \mathrm{~S}_{0}$ ground states to the ${ }^{3} \mathrm{P}_{1}$ excited states, and next, after phonon-assisted nonradiative relaxation, they relax to the ${ }^{3} \mathrm{P}_{0}$ excited levels and next $\mathrm{Bi}^{3+}$ ions can relax to the ${ }^{1} \mathrm{~S}_{0}$ ground states by emitting photons in the yellow region or through the resonance energy transfer to the nearest $\mathrm{Bi}^{3+}$ or $\mathrm{Nd}^{3+}$ ions. The energy of excited $\mathrm{Bi}^{3+}$ ions can be also transferred by the energy migration process to the unexcited neighboring $\mathrm{Bi}^{3+}$ ions, which leads to LCQ of $\mathrm{Bi}^{3+}$ ions. The other possible energy transfer processes from ${ }^{3} \mathrm{P}_{1}$ level of $\mathrm{Bi}^{3+}$ ions are the relaxations to the lower-laying exciting levels of $\mathrm{Nd}^{3+}$ ions: ${ }^{2} \mathrm{P}_{1 / 2}$, ${ }^{2} \mathrm{~K}_{15 / 2},{ }^{4} \mathrm{G}_{7 / 2}+{ }^{4} \mathrm{G}_{9 / 2},{ }^{2} \mathrm{~K}_{13 / 2},{ }^{4} \mathrm{G}_{5 / 2}+{ }^{2} \mathrm{G}_{7 / 2},{ }^{2} \mathrm{H}_{11 / 2}$, ${ }^{4} \mathrm{~F}_{9 / 2},{ }^{4} \mathrm{~F}_{7 / 2}+{ }^{4} \mathrm{~S}_{3 / 2},{ }^{4} \mathrm{~F}_{5 / 2}+{ }^{2} \mathrm{H}_{9 / 2}$. The excited $\mathrm{Nd}^{3+}$ ions after non-radiative relaxation to ${ }^{4} \mathrm{~F}_{3 / 2}$ level can relax through the ${ }^{4} \mathrm{~F}_{3 / 2} \rightarrow{ }^{4} \mathrm{I}_{9 / 2}$ and ${ }^{4} \mathrm{~F}_{3 / 2} \rightarrow{ }^{4} \mathrm{I}_{11 / 2}$ transitions with NIR emission near $878 \mathrm{~nm}$ and $1064 \mathrm{~nm}$, respectively. The phenomena in which one

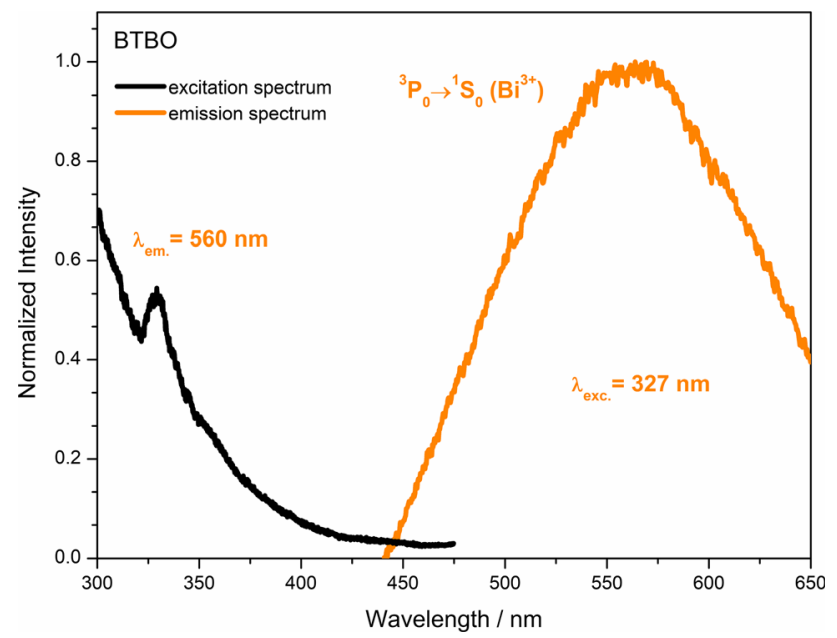

Figure 9 The excitation and emission spectra of BTBO powder for the emission observed at $560 \mathrm{~nm}$ assigned to $\mathrm{Bi}^{3+}$ ions upon the excitation at $327 \mathrm{~nm}$, recorded at $300 \mathrm{~K}$. photon of high energy can convert energy into two photons of lower energy is known as the quantum cutting process [36, 37]. The above-described energy transfer process from $\mathrm{Bi}^{3+}$ to $\mathrm{Nd}^{3+}$ leads to enhancement of $\mathrm{Nd}^{3+}$ emission in the NIR region. It should be noted that for lower concentrations of $\mathrm{Nd}^{3+}$ ions (0.5, 1.0 and 2.5 at.\%), the mentioned energy transfer process is not effective enough because all $\mathrm{Bi}^{3+}$ ions are excited, but they can transfer energy only to the selected neighboring $\mathrm{Nd}^{3+}$ ions. The optimal $\mathrm{Nd}^{3+}$ concentration for the quantum cutting process to be realized by $\mathrm{Bi}^{3+}-\mathrm{Nd}^{3+}$ pairs in the BTBO: $\mathrm{Nd}^{3+}$ system is 5.0 at.\%. For higher concentration of $\mathrm{Nd}^{3+}$ (7.5 and 10.0 at.\%) we observe the LCQ effect.

After the excitation in VIS (at $586.4 \mathrm{~nm}$ ), the $\mathrm{Nd}^{3+}$ ions are excited from the ground state ${ }^{4} \mathrm{I}_{9 / 2}$ to the excited states ${ }^{4} G_{5 / 2}+{ }^{2} G_{7 / 2}$ (the most intensive bands detected in the excitation spectra of BTBO: $\mathrm{Nd}^{3+}$ powders recorded by monitoring the emission of the ${ }^{4} \mathrm{~F}_{3 / 2} \rightarrow{ }^{4} \mathrm{I}_{11 / 2}$ transition in $\mathrm{Nd}^{3+}$ ions at $1064 \mathrm{~nm}$ ). These excited $\mathrm{Nd}^{3+}$ ions can relax to the ${ }^{4} \mathrm{~F}_{3 / 2}$ level through non-radiative relaxation and next the NIR emission can be observed at about $878 \mathrm{~nm}$ and $1064 \mathrm{~nm}$ by the ${ }^{4} \mathrm{~F}_{3 / 2} \rightarrow{ }^{4} \mathrm{I}_{9 / 2}$ and ${ }^{4} \mathrm{~F}_{3 / 2} \rightarrow{ }^{4} \mathrm{I}_{11 / 2}$ transitions, respectively. Moreover, the highest intensity NIR emission was observed for 0.5 at.\% $\mathrm{Nd}^{3+}$ concentration. For higher concentrations of $\mathrm{Nd}^{3+}$ ions $(1.0,2.5,5.0,7.5$ and 10.0 at. \%), we observed a decrease in the NIR emission as a result of

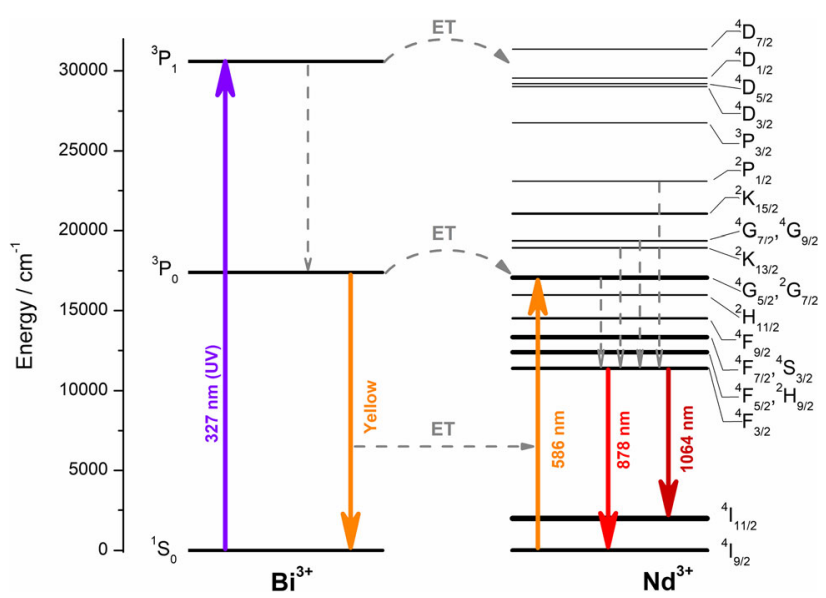

Figure 10 Schematic diagram of the possible ET between active ions in the BTBO: $\mathrm{Nd}^{3+}$ system upon the excitation at 327 and $586.4 \mathrm{~nm}$. 

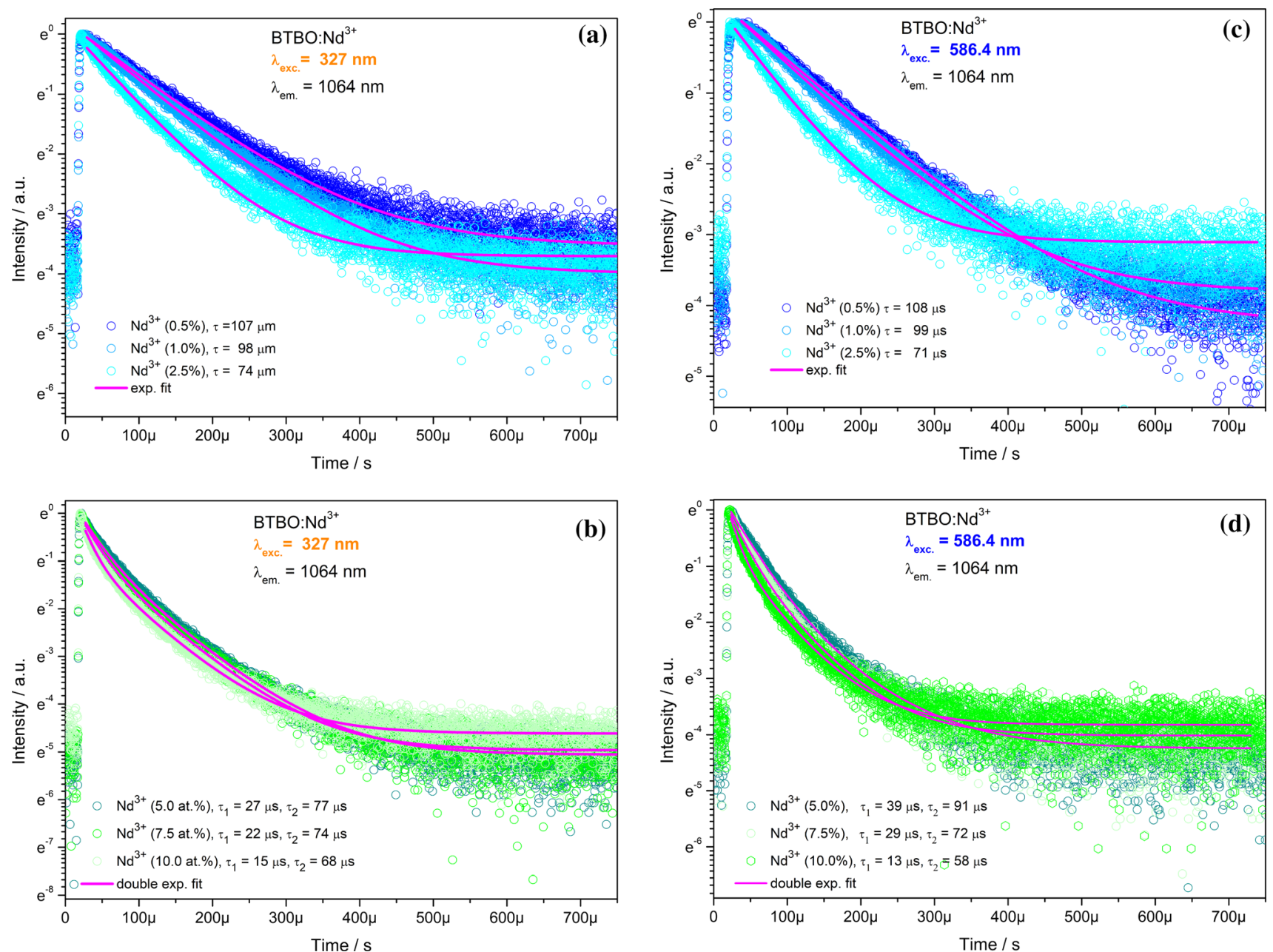

Figure 11 The luminescence decay time curves of BTBO: $\mathrm{Nd}^{3+}$ powders recorded by monitoring the emission of the ${ }^{4} \mathrm{~F}_{3 / 2} \rightarrow{ }^{4} \mathrm{I}_{11 / 2}$ transition in $\mathrm{Nd}^{3+}$ ions at $1064 \mathrm{~nm}$, upon the excitation at $327 \mathrm{~nm}(\mathbf{a})(\mathbf{b})$ and $586.4 \mathrm{~nm}(\mathbf{c})(\mathbf{d})$, detected at $300 \mathrm{~K}$.

LCQ effect due to short distances between the active $\mathrm{Nd}^{3+}$ ions.

The luminescence decay curves of BTBO: $\mathrm{Nd}^{3+}$ powders monitored for the emission at $1064 \mathrm{~nm}$ upon the excitation at 327 and $586.4 \mathrm{~nm}$ are presented in Fig. 11.

To determine the decay times, the experimental decay curves of BTBO: $\mathrm{Nd}^{3+}$ powders were fitted to the exponential function according to the following formula:

$I=I_{1} \exp \left(-\frac{t}{\tau_{1}}\right)+I_{2} \exp \left(-\frac{t}{\tau_{2}}\right)$

where $I_{1}$ and $I_{2}$ are the intensities of different luminescence processes at the initial time and $\tau_{1}$ and $\tau_{2}$ are their lifetimes, respectively [37]. For BTBO: $\mathrm{Nd}^{3+}$ powders doped with higher $\mathrm{Nd}^{3+}$ concentrations (5.0, 7.5 and 10.0 at.\%), a good fit was obtained with a double exponential function, while only one exponential function was needed for lower doped powders (0.5, 1.0 and 2.5 at.\%). The decay time determined by the spontaneous emission from the excited $\mathrm{Nd}^{3+}$ levels and the time calculated from the fit of the decay curves show the influence of the dopant concentration on the energy transfer process. The presence of two components in the decay fit is due to the different location and environment of $\mathrm{Nd}^{3+}$ ions incorporated into the BTBO lattice either in the volume or on the surface of the microcrystals, where $\mathrm{Bi}^{3+}$ ions are substituted by $\mathrm{Nd}^{3+}$ ions. Moreover, for higher concentrations of $\mathrm{Nd}^{3+}$, the surface-related effect is stronger due to higher surface to volume ratio, which results in a double exponential decay time character. The determined lifetimes monitored for the emission at $1064 \mathrm{~nm}$ under the excitation at 327 and $586.4 \mathrm{~nm}$ are given in Table 5 . 
Table 5 The lifetimes monitored for emission at $1064 \mathrm{~nm}$ upon the excitation at 327 and $586.4 \mathrm{~nm}$

\begin{tabular}{|c|c|c|c|c|}
\hline \multirow[t]{2}{*}{ Compound } & \multicolumn{2}{|c|}{$\lambda_{\text {exc. }}=327 / \mathrm{nm}$} & \multicolumn{2}{|c|}{$\lambda_{\text {exc. }}=586.4 / \mathrm{nm}$} \\
\hline & $\tau / \mu \mathrm{s}$ & & $\tau / \mu \mathrm{s}$ & \\
\hline BTBO $\mathrm{Nd}^{3+}(0.5$ at $\%)$ & 107 & & 108 & \\
\hline BTBO $\mathrm{Nd}^{3+}(1.0$ at $\%)$ & 98 & & 99 & \\
\hline BTBO Nd ${ }^{3+}(2.5$ at\%) & 74 & & 71 & \\
\hline & $\tau_{1} / \mu \mathrm{s}$ & $\tau_{2} / \mu \mathrm{s}$ & $\tau_{1} / \mu \mathrm{s}$ & $\tau_{2} / \mu \mathrm{s}$ \\
\hline BTBO $\mathrm{Nd}^{3+}(5.0 \mathrm{at} \%)$ & 27 & 77 & 39 & 91 \\
\hline BTBO $\mathrm{Nd}^{3+}(7.5$ at\%) & 22 & 74 & 29 & 72 \\
\hline BTBO $\mathrm{Nd}^{3+}(10.0$ at $\%)$ & 15 & 68 & 13 & 58 \\
\hline
\end{tabular}

As follows from Table 5, the maximum lifetimes $\tau$ equal 107 and $108 \mu \mathrm{s}$ were obtained for the BTBO: $\mathrm{Nd}^{3+}$ samples with the lowest concentration of $\mathrm{Nd}^{3+}(0.5$ at.\%), both under the excitation at 327 and $586.4 \mathrm{~nm}$. For the other samples (1.0 and 2.5 at.\% concentration of $\mathrm{Nd}^{3+}$ ), the lifetimes $\tau$ were shorter due to a weak $\mathrm{Nd}^{3+}-\mathrm{Nd}^{3+}$ interaction resulting in the LCQ effect. For the BTBO: $\mathrm{Nd}^{3+}$ samples with higher concentration of $\mathrm{Nd}^{3+}$ ions (5.0, 7.5 and 10.0 at.\%), the lifetimes $\tau_{1}$ and $\tau_{2}$ related to the above-mentioned different location of $\mathrm{Nd}^{3+}$ ions (in the surface and in the volume of microcrystals, respectively) were determined. Moreover, as presented in Table 2, we observed the lifetimes to decrease with increasing $\mathrm{Nd}^{3+}$ concentration, both for $\tau_{1}$ and $\tau_{2}$.

Additionally, the presented experimental results for BTBO: $\mathrm{Nd}^{3+}$ powders were supported by the following analysis and calculations. As mentioned above, the LCQ effect and shortening of the lifetime $\tau$ for BTBO: $\mathrm{Nd}^{3+}$ powders strongly depend on the concentration $N_{A}$ of active $\mathrm{Nd}^{3+}$ ions, which can be calculated using the following equation:

$N_{A}=\frac{3 Z x}{V}$

where $V$ is the unit-cell volume, $x$ is the dopant concentration and $Z$ is the number of formula units in the unit cell [35]. The calculated $N_{A}$ values for BTBO: $\mathrm{Nd}^{3+}$ powders are equal $7.68,15.36,38.38$, $76.89,115.62$ and $154.29\left(\times 10^{25}\right.$ ions $\left./ \mathrm{m}^{3}\right)$ for $x=0.005,0.010,0.025,0.050,0.075$ and 0.100 , respectively. The effective energy transfer process from the excited (donors $D$ ) to the unexcited (acceptors $A$ ) $\mathrm{Nd}^{3+}$ ions depends on the distance between them. The average distance $R_{D A}$ between the $D$ and $A$ ions can be calculated from the following formula:

$R_{D A} \approx 2\left(\frac{3 V}{4 \pi x Z}\right)^{1 / 3}$

where $V$ is the unit-cell volume, $x$ is the dopant concentration and $Z$ is the number of formula units in the unit cell [35]. The average distance $R_{D A}$ for the investigated BTBO: $\mathrm{Nd}^{3+}$ powders calculated using Eq. 7 is equal $42.1,33.4,24.6,19.5,17.1,15.5 \AA$ for $x=0.005,0.010,0.025,0.050,0.075$ and 0.100, respectively. The relatively high values of $R_{D A}$ in the investigated BTBO: $\mathrm{Nd}^{3+}$ powders indicate that the main energy transfer mechanism responsible for the LCQ effect and shortening of the lifetime $\tau$ is the electric interaction [35].

Furthermore, for BTBO: $\mathrm{Nd}^{3+}$ powder with the lowest concentration of $\mathrm{Nd}^{3+}$ ions $(0.5$ at.\%), the decay curve was analyzed using the Inokuti-Hirayama (IH) model [38]. In the $\mathrm{IH}$ model, the kinetics of the fluorescence intensity was described by the following equation:

$I(t)=\mathrm{I}_{0} \exp \left[-\frac{t}{\tau_{0}}-Q\left(\frac{t}{\tau_{o}}\right)^{\frac{3}{s}}\right]+b$

where $\tau_{0}$ is the intrinsic decay time of $D$ ions in the absence of $A$ ions; $b$ is the fitting offset; $Q$ is the energy transfer parameter. The decay curve of BTBO: $\mathrm{Nd}^{3+}$ (0.5 at.\%) powder was well fitted to the $\mathrm{IH}$ models for the measured fluorescence lifetime $\tau_{0}=108 \mu$ s (of the ${ }^{4} \mathrm{~F}_{3 / 2} \rightarrow{ }^{4} \mathrm{I}_{11 / 2}$ transition upon the excitation with $586.4 \mathrm{~nm}$ ) and $s=6$. The value of $s=6$, which was used during the fitting procedure, suggests the dipole-dipole interaction as the main mechanism of the energy transfer in the BTBO: $\mathrm{Nd}^{3+}$ (0.5 at.\%) powder [35]. Moreover, the energy transfer parameter $Q$ can be determined from the fitting procedure using the following formula:

$Q=\frac{4}{3} \pi \Gamma\left(1-\frac{3}{s}\right) N_{A} R_{o}^{3}$

where $\Gamma$ is the function taking the values of 1.77 for the dipole-dipole interaction [35], $R_{o}$ is the critical distance and $N_{A}$ is the concentration of $A$ ions.

Assuming the IH model, the energy transfer rate $W_{E T}$ was calculated using the following equation: 
$W_{\mathrm{ET}}\left(R_{\mathrm{DA}}\right)=\frac{C_{\mathrm{DA}}^{(s)}}{R_{\mathrm{DA}}^{(s)}}$

where $R_{D A}$ is the average distance between $D$ and $A$ ions, the value of $s$ is equal to 6 for the dipole-dipole interaction [35] and $C_{D A}$ is the energy transfer microparameter estimated by analyzing the decay profile using the following relation [39]:

$\mathrm{C}_{\mathrm{DA}}=R_{o}^{s} \tau_{o}^{-1}$

where the value of $R_{o}=3.48 \AA$ was calculated from the transformed Eq. 9.

Finally, according to the IH model, the following energy transfer parameters for BTBO: $\mathrm{Nd}^{3+}(0.5$ at.\%) powder were determined: $Q=0.12$, the energy transfer micro-parameter $C_{D A}=\left(1.60 \times 10^{-53}\right) \mathrm{m}^{6} / \mathrm{s}$ and the energy transfer rate $W_{E T}=0.003 \mathrm{~s}^{-1}$. Moreover, for BTBO: $\mathrm{Nd}^{3+}$ powders with the higher $\mathrm{Nd}^{3+}$ concentrations (1.0, 2.5, 5.0, 7.5 and 10.0 at.\%), the decay curves were not well fitted to the IH model and the observed shortening of the lifetime $\tau$ indicates some other energy transfer processes between the $D$ and $A$ ions such as the resonant energy migration or cross-relaxation [40].

\section{Conclusions}

The investigated BTBO: $\mathrm{Nd}^{3+}$ microcrystalline powders doped with $\mathrm{Nd}^{3+}$ ions in various concentrations $(0.5,1.0,2.5,5.0,7.5$ and 10.0 at. \%) were synthesized by means of the modified Pechini method. Their phase uniformity (hexagonal structure of $P 6_{3}$ space group) was confirmed by XRD. On the basis of the Raman spectra of BTBO: $\mathrm{Nd}^{3+}$ powders, the phonon energy of BTBO matrix associated with vibrations of the characteristic $\mathrm{BO}_{3}$ and $\mathrm{TeO}_{6}$ molecular groups was determined. The relatively low phonon energy of BTBO matrix allows effective phonon assisted energy transfer between $\mathrm{Bi}^{3+}$ and $\mathrm{Nd}^{3+}$ active ions. The excitation spectrum of $\mathrm{BTBO}$ for $\mathrm{Bi}^{3+}$ ions emission in VIS (with maximum intensity at about $560 \mathrm{~nm}$ ) shows the band at $327 \mathrm{~nm}$. The excitation spectra of BTBO: $\mathrm{Nd}^{3+}$ for $\mathrm{Nd}^{3+}$ ions emission at $1064 \mathrm{~nm}$ show the bands related to the $f-f$ optical transitions of $\mathrm{Nd}^{3+}$ ions as well as the bands related to the ${ }^{1} \mathrm{~S}_{0} \rightarrow{ }^{3} \mathrm{P}_{1}$ transition of $\mathrm{Bi}^{3+}$ ions at about $327 \mathrm{~nm}$. The emission spectra of BTBO: $\mathrm{Nd}^{3+}$ powders excited at $327 \mathrm{~nm}$ (by $\mathrm{Bi}^{3+}$ ions) and at $586.4 \mathrm{~nm}$ (by $\mathrm{Nd}^{3+}$ ions) show relatively strong luminescence at about 878 and
$1064 \mathrm{~nm}$ arising from the ${ }^{4} \mathrm{~F}_{3 / 2} \rightarrow{ }^{4} \mathrm{I}_{9 / 2}$ and ${ }^{4} \mathrm{~F}_{3} /$ ${ }_{2} \rightarrow{ }^{4} \mathrm{I}_{11 / 2}$ transitions of $\mathrm{Nd}^{3+}$ ions, respectively. The higher intensity emission bands in NIR for the excitation in $\mathrm{UV}$ (by $\mathrm{Bi}^{3+}$ ions) were detected in the spectra of the BTBO: $\mathrm{Nd}^{3+}$ powders doped with higher concentrations of $\mathrm{Nd}^{3+}$ ions (5.0, 7.5 and 10 at.\%), with the maximum for 5.0 at.\% concentration. So, the optimal $\mathrm{Nd}^{3+}$ concentration for the quantum cutting process to be realized by $\mathrm{Bi}^{3+}-\mathrm{Nd}^{3+}$ pairs in the BTBO: $\mathrm{Nd}^{3+}$ system is 5.0 at.\%. for the excitation in UV (by $\mathrm{Bi}^{3+}$ ions). For higher concentration of $\mathrm{Nd}^{3+}$ (7.5 and 10.0 at.\%), we observe the LCQ effect. For the excitation in VIS (by $\mathrm{Nd}^{3+}$ ions), higher intensity of emission bands in NIR was detected in the spectra of BTBO: $\mathrm{Nd}^{3+}$ powders doped with lower concentrations of $\mathrm{Nd}^{3+}$ ions $(0.5,1.0$ and 2.5 at.\%) with the maximum for 0.5 at.\% concentration. For higher concentrations of $\mathrm{Nd}^{3+}$ ions (1.0, 2.5, 5.0, 7.5 and 10.0 at. \%), we observed a decrease in the NIR emission as a result of LCQ effect due to short distances between the active $\mathrm{Nd}^{3+}$ ions. Moreover, the longest fluorescence decay lifetimes monitored at $1064 \mathrm{~nm}$ are equal 107 and $108 \mu \mathrm{s}$ for the BTBO: $\mathrm{Nd}^{3+}$ sample with the lowest concentration of $\mathrm{Nd}^{3+}(0.5$ at.\%), upon the excitation at 327 and $586.4 \mathrm{~nm}$, respectively. For BTBO: $\mathrm{Nd}^{3+}$ powders with higher concentration of $\mathrm{Nd}^{3+}$ ions, the fluorescence decay lifetimes change character and decrease due to the increasing significance of the surface-related effect. Moreover, the observed phenomena result from different energy transfer mechanisms upon the excitation in UV (by $\mathrm{Bi}^{3+}$ ions) and excitation in VIS spectral range (by $\mathrm{Nd}^{3+}$ ions). Due to the energy transfer process from $\mathrm{Bi}^{3+}$ to $\mathrm{Nd}^{3+}$, the enhancement of $\mathrm{Nd}^{3+}$ emission in the NIR region is observed in BTBO: $\mathrm{Nd}^{3+}$ systems. As a result, due to good optical and luminescence properties, the BTBO: $\mathrm{Nd}^{3+}$ microcrystalline powders can be potentially used as an efficient UV/VIS to NIR spectral converters for new generation c-Si solar cells.

\section{Acknowledgements}

This work was supported by the Research Project of the Polish Ministry of Sciences and Higher Education: 0511/SBAD/2151. We would like to thanks dr. B. Macalik for diffuse-reflectance spectra measurements. 


\section{Declarations}

Conflict of interest The authors declare that they have no conflict of interest.

Supplementary Information: The online version contains supplementary material available at http s://doi.org/10.1007/s10853-021-06642-2.

Open Access This article is licensed under a Creative Commons Attribution 4.0 International License, which permits use, sharing, adaptation, distribution and reproduction in any medium or format, as long as you give appropriate credit to the original author(s) and the source, provide a link to the Creative Commons licence, and indicate if changes were made. The images or other third party material in this article are included in the article's Creative Commons licence, unless indicated otherwise in a credit line to the material. If material is not included in the article's Creative Commons licence and your intended use is not permitted by statutory regulation or exceeds the permitted use, you will need to obtain permission directly from the copyright holder. To view a copy of this licence, visit http://creativecommons.org/licen ses/by $/ 4.0 /$.

\section{References}

[1] Van Sark WGJHM, Meijerink A, Schropp REI (2012) Third Generations Photovoltaics. V. Fthenakis, InTech: Rijeka. h ttps://doi.org/10.5772/39213

[2] Thillier G, Hersee M, Labs D, Foujols T, Peetemans W, Gillotay D, Simon PC, Mandel H (2003) The solar spectral irradiance from 200 to $2400 \mathrm{~nm}$ as measured by the solspec spectrometer from the Atlas and Eureca Missions. Sol Phys 214:1-22. https://doi.org/10.1023/A:1024048429145

[3] Poman A, Knight M, Garnett EC, Ehrler B, Sinke C (2016) Photovoltaic materials: present efficiencies and future challenges. Sci 352:6283. https://doi.org/10.1126/science.aad 4424

[4] Jung S, Gong D, Yi J (2011) The effects of the band gap and defects in silicon nitride on the carrier lifetime and the transmittance in c-Si solar cells. Sol Energ Mat Sol C 95:546-550. https://doi.org/10.1016/j.solmat.2010.09.014

[5] Sharma S, Jain KK, Sharma A (2015) Solar cells. in research and applications a review. MSA 6:1145-1155. https://doi. org/10.4236/msa.2015.612113
[6] Chen P, Murshed MM, Gesing TM (2021) Synthesis and crystal structures of novel alkali rare-earth orthoborates $\mathrm{K}_{3-}$ $\mathrm{RE}_{3}\left(\mathrm{BO}_{3}\right)_{4} \quad(\mathrm{RE}=\mathrm{Pr}, \mathrm{Nd}, \quad \mathrm{Sm}-\mathrm{Lu}) . \quad \mathrm{J}$ Mater Sci 56:3639-3652. https://doi.org/10.1007/s10853-020-05506-5

[7] Dos Santos DF, Lovisa LX, Santiego AAG, Li MS, Longo E, Bomio MRD, Motta FV (2020) Growth mechanism and vibrational and optical properties of $\mathrm{SrMoO}_{4}: \mathrm{Tb}^{3+}, \mathrm{Sm}^{3+}$ particles: green-orange tunable color. $\mathrm{J}$ Mater Sci 55:8610-8629. https://doi.org/10.1007/s10853-020-04623-5

[8] Jaroszewski K, Głuchowski P, Brik MG, Pedzinski T, Majchrowski A, Chrunik M, Michalski E, Kasprowicz D (2017) Bi-funtional $\mathrm{Bi}_{2} \mathrm{ZnOB}_{2} \mathrm{O}_{6}: \mathrm{Nd}^{3+}$ single crystals for infrared lasers: luminescence and $\mu$-Raman investigations. Cryst Growth Des 17:3656-3664. https://doi.org/10.1021/acs.cgd. $7 \mathrm{~b} 00016$

[9] Xia M, Jiang X, Lin Z, Li R (2016) “All-Three-in-One": A new bismuth-tellurium-borate $\mathrm{Bi}_{3} \mathrm{TeBO}_{9}$ exhibiting strong second harmonic generation response. J Am Chem Soc 138:14190-14193. https://doi.org/10.1021/jacs.6b08813

[10] Daub M, Krummer M, Hoffmann A, Bayarjargal L, Hillebrecht $\mathrm{H}$ (2016) Synthesis, crystal structure, and properties of $\mathrm{Bi}_{3} \mathrm{TeBO}_{9}$ or $\mathrm{Bi}_{3}\left(\mathrm{TeO}_{6}\right)\left(\mathrm{BO}_{3}\right)$ : A non-centrosymmetric borate-tellurate(VI) of bismuth. Chem Eur J 22:1-8. https://doi.org/10.1002/chem.201602480

[11] Majchrowski A, Chrunik M, Rudysh M, Piasecki M, Ozga K, Lakshminarayana G, Kityk IV (2017) $\mathrm{Bi}_{3} \mathrm{TeBO}_{9}$ : electronic structure, optical properties and photoinduced phenomena. J Mater Sci 53:1217-1226. https://doi.org/10.1007/ s10853-017-1554-z

[12] Zhong M, Liu QJ, Jiang CL, Liu FS, Tang B, Peng XJ (2018) Structural, elastic, electronic, phonon, dielectric and optical properties of $\mathrm{Bi}_{3} \mathrm{TeBO}_{9}$ from first-principles calculations. J Phys Chem Solids 121:139-144. https://doi.org/10. 1016/j.jpcs.2018.05.026

[13] Kasprowicz D, Zhezhera T, Lapinski A, Chrunik M, Majchrowski A, Kityk AV, Shchur Y (2019) Lattice dynamics of novel $\mathrm{Bi}_{3} \mathrm{TeBO}_{9}$ microcrystals: $\mu$-Raman/IR spectroscopic investigation and $\mathrm{ab}$ initio analysis. J Alloys Comp 782:488-495. https://doi.org/10.1016/j.jallcom.2018.12.137

[14] Wyart JF, Meftah A, Bachelier A, Sinzelle J, Tchang-Brillet L, Champion N, Spector N, Sugar J (2006) Energy levels of $4 \mathrm{f}^{3}$ in the $\mathrm{Nd}^{3+}$ free ion from emission spectra. J Phys B At Mol Opt Phys 39:77-82. https://doi.org/10.1088/0953-4075/ 39/5/L01

[15] Huang XY, Zhang QY (2010) Near-infrared quantum cutting via cooperative energy transfer in $\mathrm{Gd}_{2} \mathrm{O}_{3}: \mathrm{Bi}^{3+}, \mathrm{Y}^{\mathrm{b} 3}+$ phosphors. J Appl Phys 107:063505. https://doi.org/10.1063/1. 3354063

[16] Wang Y, Guo N, Shao B, Yao C, Ouyang R, Miao Y (2021) Adjustable photoluminescence of $\mathrm{Bi}^{3+}$ and $\mathrm{Eu}^{3+}$ in solid 
solution constructed by isostructural end components through composition and excitation-driven strategy. Chem Eng J 421:127735. https://doi.org/10.1016/j.cej.2020. 127735

[17] Bale S, Rahman S, Awasthi AM, Sathe V (2008) Role of $\mathrm{Bi}_{2} \mathrm{O}_{3}$ content on physical, optical and vibrational studies in $\mathrm{Bi}_{2} \mathrm{O}_{3}-\mathrm{ZnO}-\mathrm{B}_{2} \mathrm{O}_{3}$ glasses. J Alloys Comp 460:699-703. https://doi.org/10.1016/j.jallcom.2007.06.090

[18] Lyu T, Dorenbos P (2019) Designing thermally stimulated $1.06 \mu \mathrm{m} \mathrm{Nd}^{3+}$ emission for the second bio-imaging window demonstrated by energy transfer from $\mathrm{Bi}^{3+}$ in $\mathrm{La}, \mathrm{Gd}, \mathrm{Y}$, and $\mathrm{LuPO}_{4}$. Chem Eng J 372:978-991. https://doi.org/10.1016/ j.cej.2019.04.125

[19] Liu GX, Zhang R, Xiao QL, Zou SY, Peng WF, Cao LW, Meng JX (2011) Efficient $\mathrm{Bi}^{3+} \rightarrow \mathrm{Nd}^{3+}$ energy transfer in $\mathrm{Gd}_{2} \mathrm{O}_{3}: \mathrm{Bi}^{3+}, \mathrm{N}^{\mathrm{d} 3}+$. Opt Mater 34:313-316. https://doi.org/ 10.1016/j.optmat.2011.09.003

[20] Dexter DL (1954) Theory of concentration quenching in inorganic phosphors. J Chem Phys 22:1063. https://doi.org/ $10.1063 / 1.1740265$

[21] Ostroumov V, Jensen T, Meyn JP, Huber G, Noginov MA (1998) Study of luminescence concentration quenching and energy transfer upconversion in Nd-doped $\mathrm{LaSc}_{3}\left(\mathrm{BO}_{3}\right)_{4}$ and $\mathrm{GdVO}_{4}$ laser crystals. JOSA B 15:1052-1060. https://doi. org/10.1364/JOSAB.15.001052

[22] Azkargorta J, Marciniak L, Iparraguirre I, Balda R, Strek W, Barredo-Zuriarrain M, Garcia-Revilla S, Fernandez J (2017) Influence of grain size and $\mathrm{Nd}^{3+}$ concentration on the stimulated emission of $\mathrm{LiLa}_{1-\mathrm{x}} \mathrm{Nd}_{\mathrm{x}} \mathrm{P}_{4} \mathrm{O}_{12}$ crystal powders. Opt Mater 63:46-50. https://doi.org/10.1016/j.optmat.2016. 07.016

[23] Suo H, Zhao X, Zhang Z, Guo C (2020) Ultra-sensitive optical nano-thermometer $\mathrm{LaPO}_{4}: \mathrm{Yb}^{3+} / \mathrm{Nd}^{3+}$ based on thermo-enhanced NIR-to-NIR emissions. Chem Eng J 389:124506. https://doi.org/10.1016/j.cej.2020.124506

[24] Pechini MP (1967) Method of preparing lead and alkaline earth titanates and niobates and coating method using the same to form a capacitor. U.S. Patent No. 3,330,697. Washington, DC: U.S. Patent and Trademark Office.

[25] Bencs L, Szakacs O, Kantor T, Varga I, Bozsai G (2000) Determination of chromium, molybdenum and vanadium dopants in bismuth tellurite optical crystals by multi-element graphite furnace atomic absorption spectrometry. Spectrochim Acta Part B At Spectrosc 55:883-891. https://doi. org/10.1016/S0584-8547(00)00221-4

[26] Cong R, Yang T, Lin Z, Bai L, Ju J, Liao F, Wang Y, Lin J (2021) Rare earth induced formation of $\delta$-BiB3O6 at ambient pressure with strong second harmonic generation. J Mater Chem 22:17934-17941. https://doi.org/10.1039/ C2JM32744A
[27] Diamond Version 2.1c (1998) Visual crystal structure information system, crystal impact GbR, Germany

[28] Shannon RD (1976) Revised effective ionic radii and systematic studies of interatomic distances in halides and chalcogenides. Acta Cryst A 43:751-767. https://doi.org/10. 1107/S0567739476001551

[29] Rousseau DL, Bauman RP, Porto SPS (1981) Normal mode determination in crystals. J Raman Spectrosc 10:253-290. https://doi.org/10.1002/jrs.1250100152

[30] Turrell G (1972) Infrared and raman spectra of crystals. J Mol Struct 16:504-505. https://doi.org/10.1016/0022-286 0(73)80119-X

[31] Xia HR, Li LX, Teng B, Zheng WQ, Lu GW, Jiang HD, Wang JY (2002) Raman scattering from bismuth triborate. J Raman Spectrosc 33:278-282. https://doi.org/10.1002/jrs. 847

[32] Kasprowicz D, Runka T, Jaroszewski K, Majchrowski A, Michalski E (2014) Vibrational properties of nonlinear optical Bi2ZnOB2O6 single crystals doped with Pr3+: $\mu$ Raman investigations. J Alloys Comp 610:600-605. https://doi.org/10.1016/j.jallcom.2014.05.071

[33] Dieke GH, Crosswhite HM, Crossawhite H (1968) Spectra and energy levels of rare-earth ions in crystals. Interscience Publishers, New York

[34] Marciniak L, Bednarkiewicz A, Stefanski M, Tomala R, Hreniak D, Strek W (2015) Near infrared absorbing near infrared emitting highly-sensitive luminescent nanothermometer based on $\mathrm{Nd}^{3+}$ to $\mathrm{Yb}^{3+}$ energy transfer. Phys Chem Chem Phys 17:24315-24321. https://doi.org/10.1039/ $\mathrm{C} 5 \mathrm{CP} 03861 \mathrm{H}$

[35] Blasse G (1968) Energy transfer in oxidic phosphors. Phys Lett A 28:444-445. https://doi.org/10.1016/0375-9601(68)9 0486-6

[36] Li J, Zhang S, Luo H, Mu Z, Li Z, Du Q, Feng J, Wu F (2018) Efficient near ultraviolet to near infrared down conversion photoluminescence of $\mathrm{La}_{2} \mathrm{GeO}_{5}: \mathrm{Bi}^{3+}, \mathrm{Nd}^{3+}$ phosphor for silicon-based solar cells. Opt Mater 85:523-530. https://doi.org/10.1016/j.optmat.2018.09.024

[37] Guo S, Zhang S, Mu Z, Wu F, Feng X, Zhang Q, Feng J, Zhu D, Du Q (2019) Enhanced near infrared luminescence of $\mathrm{Lu}_{2} \mathrm{GeO}_{5}: \mathrm{Nd}^{3+}$ by the co-doping of $\mathrm{Bi}^{3+}$. J Lumin 206:278-283. https://doi.org/10.1016/j.jlumin.2018.10.029

[38] Inokuti M, Hirayama F (1965) Influence of energy transfer by the exchange mechanism on donor luminescence. J Chem Phys 43:1978-1989. https://doi.org/10.1063/1.1697063

[39] Solarz P, Ryba-Romanowski W (2007) Energy transfer processes in $\mathrm{K}_{5} \mathrm{Li}_{2} \mathrm{GdF}_{10}$ :Eu. Pr Radiat Meas 42:759-762. https://doi.org/10.1016/j.radmeas.2007.02.007

[40] Martin IR, Rodriguez VD, Rodriguez-Mendoza UR, Lavin V, Montoya E, Jacque D (1999) Energy transfer with 
migration. Generalization of the Yokota-Tanimoto model for any kind of multipole interaction. J Chem Phys 111:1191-1194. https://doi.org/10.1063/1.479304
Publisher's Note Springer Nature remains neutral with regard to jurisdictional claims in published maps and institutional affiliations. 